\title{
Using albedo to reform wind erosion modelling, mapping and monitoring
}

Adrian Chappell ${ }^{1 *}$, Nicholas P. Webb ${ }^{2}$

${ }^{1}$ CSIRO Land and Water, G.P.O. Box 1666, Canberra ACT 2601, Australia

${ }^{2}$ USDA-ARS Jornada Experimental Range, Las Cruces, New Mexico, USA

*Corresponding author:

Email: ges309@yahoo.co.uk 


\section{Abstract}

Wind erosion and dust emission models are used to assess the impacts of dust on radiative forcing in the atmosphere, cloud formation, nutrient fertilisation and human health. The models are underpinned by a twodimensional geometric property (lateral cover; $L$ ) used to characterise the three-dimensional aerodynamic roughness (sheltered area or wakes) of the Earth's surface and calibrate the momentum it extracts from the wind. We reveal a fundamental weakness in $L$ and demonstrate that values are an order of magnitude too small and significant aerodynamic interactions between roughness elements and their sheltered areas have been omitted, particularly under sparse surface roughness $(0.001<L<0.1)$. We describe a solution which develops published work to establish a relation between sheltered area and the proportion of shadow over a given area; the inverse of direct beam directional hemispherical reflectance (black sky albedo; BSA). We show direct relations between shadow and wind tunnel measurements and thereby provide direct calibrations of key aerodynamic properties. Estimation of the aerodynamic parameters from albedo enables wind erosion assessments over areas, across platforms from the field to airborne and readily available satellite data. Our new approach demonstrated redundancy in existing wind erosion models and thereby reduced model complexity but improved fidelity. We found that the use of albedo enabled an adequate description of aerodynamic sheltering to characterise fluid dynamics and predict sediment transport without the use of a drag partition scheme $\left(R_{t}\right)$ or threshold friction velocity $\left(u *_{t}\right)$. We applied the calibrations to produce global maps of aerodynamic properties which showed very similar spatial patterns to each other and confirmed the redundancy in the traditional parameters of wind erosion modelling. The global maps identified regions of small aerodynamic roughness previously thought to be susceptible to wind erosion because of their erodibility. We evaluated temporal patterns of predicted horizontal mass flux at locations across Australia which revealed variation between land cover types that would not be detected using traditional models. Our new approach provides new opportunities to investigate the dynamics of wind erosion in space and time and elucidate aeolian processes across scales.

\section{Introduction}

Wind erosion and dust emission are driven by the turbulent transfer of momentum from the fluid to the land surface (Shao et al., 2015). The aerodynamic turbulence is influenced by surface roughness across a range of scales from the soil grain $(\mathrm{mm})$ to the landscape $(\mathrm{km})$. At these scales, roughness elements comprise individual landforms (e.g., dunes), vegetation (trees, shrubs, grasses) which may be photosynthetic or non-photosynthetic, and the exposed soil surface which may be rough or smooth depending on the presence of physical, chemical or biogenic crusts, the soil texture, natural structures (rocks) or management-induced features (clods, furrows). All of these roughness elements have a spatial arrangement (or spatial dependence) originating from the processes which formed them. Dunes are aligned with wind flows (Lancaster, 2013), vegetation may be aligned with wind, water or nutrient flows (Okin et al., 2015) and the soil surface may have structure within and between vegetation patches due to natural or human-induced patterns (Webb and Strong, 2011). All of these roughness elements are temporally variable or dynamic. Within any particular timeframe the surface roughness causes a highly anisotropic extraction of wind momentum relative to its direction. Natural heterogeneous mixtures of roughness elements produce highly variable aerodynamic turbulence and momentum extraction which are responsible for the magnitude and spatial patterns of wind erosion and dust emission (Gillette, 1999).

The seminal work of Bagnold (1941) provided the foundation for numerous subsequent field studies to investigate the relation between wind velocity profiles, aerodynamic turbulence and point-based sediment transport. Much of the knowledge about the spatial and temporal variation of aerodynamic turbulence across scales is gained from point-based field work and wind tunnel studies (e.g. Marshall, 1971; Gillette and Stockton, 1989; Wolfe and Nickling, 1996; Lancaster and Baas, 1998; Gillies et al., 2000, 2007; Crawley and Nickling, 2003; King et al., 2006; Brown et al., 2008; Webb et al., 2014). Wind tunnel studies have also replicated the fieldwork and isolated the controlling factors to improve our understanding of aerodynamic turbulence, roughness $\left(z_{0}\right)$ and transport feedbacks (Duran et al., 2011; Charru et al., 2013; Jenkins and Valance, 2014). Accurate estimation of 
sediment transport rates is dependent on capturing the aerodynamic roughness feedbacks to saltation, which affect the scaling of transport rates with the area-integrated (areal) momentum flux and ultimately the magnitude of dust emissions from given areas.

At the landscape scale, wind velocity profiles have been used to determine the aerodynamic roughness for diverse vegetation and surface roughness conditions (e.g. MacKinnon et al., 2004; Gillette et al., 2006). These measurements include heterogeneous combinations of roughness scales, orientations and anisotropic responses to roughness elements. However, little consideration has been given to the upstream area, and therefore which mixtures of roughness elements, influence $z_{0}$ and hence which scale has contributed most. Andre and Blondin (1986) and Taylor (1987) suggested that the integrated roughness length is strongly influenced by its spatial variability. Wieringa (1993) indicated that relatively rough patches contribute more to the effective aerodynamic roughness of a surface than their area fraction. The confounding anisotropic interaction between wind direction, contributing area and roughness scale is consistently omitted from studies (Chappell et al., 2010; Smith et al., 2016). Raupach and Lu (2004) questioned the extent to which wind erosion and dust emission models, developed to represent processes at the point scale, are applicable to heterogeneous situations over large areas or pixels. Although improved accuracy of measurement and statistical modelling (Bauer et al., 1992) has reduced uncertainty in the estimation of $z_{0}$ from wind velocity profiles, this standardisation may have distracted research in this field from establishing the uncertainty from the many sources of variance. For example, if masts of anemometers were placed at different locations within a given area or pixel (measuring at the same time without interfering with the wind flow) they would most likely provide wind velocity profiles with different $z_{0}$; its spatial variability. If those estimates of $z_{0}$ from within that area were unbiased samples and adequately represented the spatial variation, then the average and variance of $z_{0}$ would accurately and precisely characterise the area. Similarly, it is difficult to use a wind velocity profile from a single location to estimate the surface shear stress of an area if it is influenced by spatially varying soil surface roughness and heterogeneous vegetation elements.

There is evidently a need to establish the spatial variability or the areal average (integrated) of aerodynamic properties to more accurately account for their influence on wind erosion and dust emission. Researchers have looked to remote sensing to provide area average estimates of $z_{0}$ on the basis that light is scattered in proportion to the size and number of roughness elements within a pixel. However, the challenge, in common with many aspects of remote sensing, is to find a property that can be retrieved from reflectance data, which is related to $z_{0}$, robust across scales and may be transferred to other places or times. Greeley et al. (1991) linked wind velocity profile estimates of $z_{0}$ to radar backscatter cross sections from airborne and space borne platforms (Greeley et al., 1997). Marticorena et al. (2006) showed significant relations between radar backscatter coefficients and $z_{0}$ and proposed an empirical relation to retrieve $z_{0}$ using radar observations in the $C$ band from operational sensors. Marticorena et al. (2004) suggested a proportional relationship between the protrusion coefficient derived from a bi-directional reflectance model and geometric roughness and then to $z_{0}$. Chappell et al. (2010) established a physically-based relation between sheltered area and single scattering albedo from bi-directional reflectance models. These approaches have all shown promise for overcoming the limitations of field measurements of $z_{0}$ and direct application in representing momentum transfer in wind erosion and dust emission models.

Perhaps one of the most influential approximations in aerodynamic turbulence is that momentum extracted by roughness elements can be represented by roughness density (lateral cover or the frontal area index L; Marshall, 1971; Wooding et al., 1973). However, $L$ omits the interaction between roughness elements i.e., ignores the orientation of objects and assumes that they are isotropic within a pixel. In practice, the estimation of $L$ over large areas (regions, continents) is difficult and often approximated using classifications of cover and vegetation type from satellite remote sensing and in the case of bare surfaces, using geometry (cf. Shao et al., 1997; Marticorena et al. 2006). These practical approximations create discontinuities between land surface classes for the models and largely exclude heterogeneity due to mixtures of different surface types. This uncertainty is significant because these models are used to predict regional and global wind erosion and dust emission (e.g., Marticorena and Bergametti, 1995; Alfaro and Gomez, 1995; Shao, 2001). 
There remains a need to reduce the uncertainty associated with the estimation and parameterisation of aerodynamic turbulence for aeolian process studies using a holistic approach that works across scales of roughness. The objectives of this paper are to: outline the basis for the established method of reducing the complexity of aerodynamic turbulence using lateral cover (Raupach et al., 1993), reveal weaknesses in the lateral cover and thereby provide the rationale for a new approach based on shadow (Section 2); outline the foundation for the shadow-based approach and describe its physically-based development from Raupach's concept and show how it can be used to estimate key aerodynamic parameters (section 3); demonstrate how wind erosion modelling can be more parsimonious whilst retaining the fidelity of the processes (Section 4); illustrate the use of shadow with estimates from the Moderate Resolution Imaging Spectroradiometer (MODIS) (every 8 days and every $500 \mathrm{~m}$ ) to map and monitor areal aerodynamic parameters for wind erosion (sediment flux) across a range of land surface types and demonstrate their dynamics in space and time (Section 5); consider the implications and opportunities that this new approach provides for aeolian research across scales of variation (grain to landscape; section 6).

\section{Lateral cover and its weaknesses for wind erosion modelling}

In his seminal work, Raupach (1992) reduced the complexity of aerodynamic roughness by characterising the wake of an isolated roughness element placed on the surface using an effective shelter area ( $A$; Figure 1a). He used cylinders to represent roughness elements, assuming that they were an adequate approximation of the plant structure. He reasoned that the ground surface shear stress $\left(\tau_{s}\right)$ within $A$ should be zero and idealised $A$ as a wedge-shaped "shadow" in the lee of the roughness element (Figure 1a). Raupach (1992) provided a physical basis for this scaling (Hypothesis I) in which the shear layers bounding the wake spread at an elevation angle of order $\alpha=U_{h} / u_{*}$ (where $U_{h}$ is the mean wind velocity at height $h$ ) to the streamwise direction, similar to the inner layer of modified wind flow over a hill (Finnigan et al., 1990).
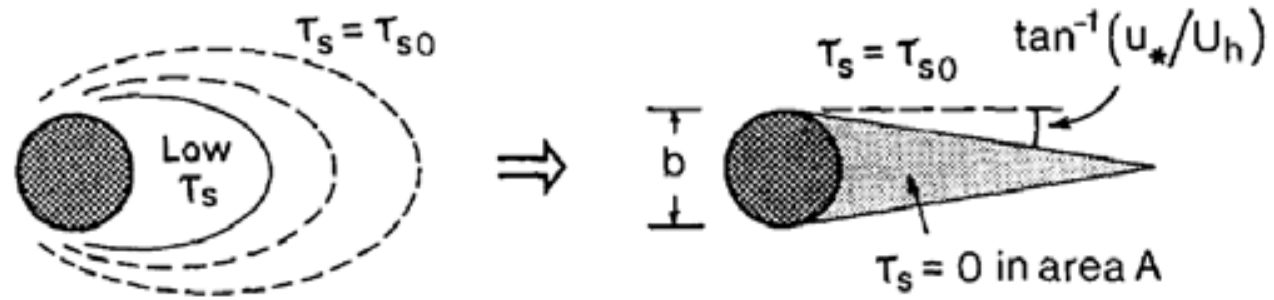

(a)

\section{Actual $\tau_{\mathrm{s}}$ contours}
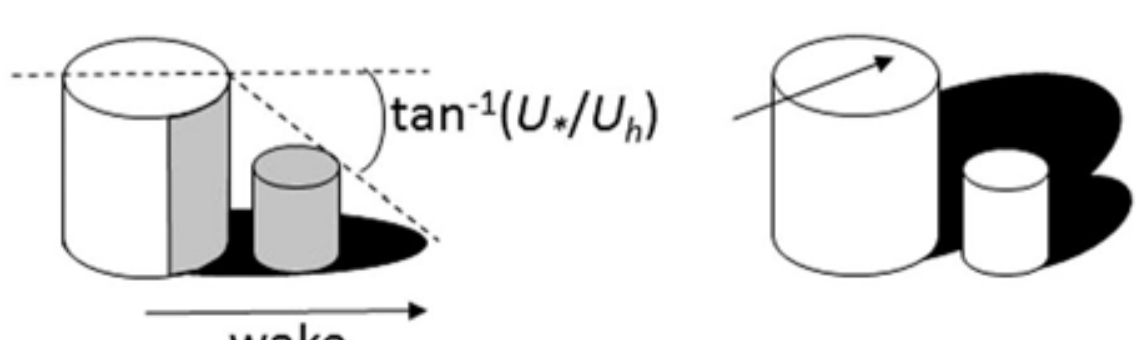

(b)

wake

Figure 1 The (a) Raupach (1992) concept for reducing the complexity of aerodynamic roughness and its representation (b) using shadow by Chappell et al., (2010) to enable an approximation using remote sensing. Reproduced from Shao et al. (2015).

Raupach (1992) assumed that the ground surface shear stress reductions in the wake of an element are spread over a region considered large relative to $A$ (Hypothesis II). This assumption considers the interaction between the elements and potential element wakes to be dependent on the roughness density (defined in the next paragraph) and not on the arrangement of roughness elements at the surface as demonstrated by Marshall's (1971) empirical study. Raupach (1992) described how neither of his hypotheses were an exact statement, but 
that both physically-based approximations permitted a straightforward analysis. Raupach's approximations represent a "quantum fluid" approach which generalises the influence on wind flow of an individual roughness element to estimate the total effect for all roughness elements in a given area (Shao et al., 2015).

However, there is an inconsistency between the approximations and the application which we explain next. The roughness density or lateral cover $(L)$ is the frontal (silhouette) area of roughness elements. For cylinders this reduces to

$L=n b h / S$

where $n$ is number of roughness elements, $b$ is their breadth, $h$ their height and $S$ the ground surface area in which the roughness element frontal area ( $b h ; b$ is breadth and $h$ is height) is projected to a smooth plane. In this approach $L$ is projected (implicitly) at an angle of $45^{\circ}\left(L_{45}\right)$ which is fixed for all surface roughness which implies that

$L_{45}=A_{45} / S=n b h \tan (45) / S$

(recall $\tan (45)=1$ hence $L=n b h / S$ ). In contrast, Raupach (1992) described in general

$A_{\alpha}=c_{1} b h U_{h} / u_{*}$

where $c_{1}=c^{\prime}{ }_{1}(b / h)^{p}$ and which implies that

$L_{\alpha}=n b h \tan (\alpha) / S$.

When calculated using Marshall's (1971) data (for simplicity setting $U_{h}=U_{f}$ the freestream velocity, $p=0$ and $c_{1}=1$ ) we found $A_{\alpha} / S=L_{\alpha}$ and that $A_{\alpha} / S \neq L_{45}$. Using Marshall's (1971) experiments of roughness elements, the $L_{45}$ was an order of magnitude smaller than that of $L_{\alpha}$. The $L_{45}$ was always $<1$ and the length of $A_{45}(h=2.54 \mathrm{~cm})$ did not exceed the spacing of the roughness elements in any of Marshall's configurations. In contrast, $\alpha$ ranged between elevation angles of $2-5^{\circ}$ (zenith angle $85-88^{\circ}$ ). For clarity, this means that the length of the shelter area is $11-27$ times either half the width of the roughness elements $(1.27-12.7 \mathrm{~cm})$ and ranged 9-164 cm, or 11-27 times the height of the roughness element $(2.54 \mathrm{~cm})$ and hence ranges between $29-68 \mathrm{~cm}$. In the latter case $L_{\alpha}$ is greater than $L_{45}$ in approximately one third of Marshall's surface roughness configurations. The length of $A_{\alpha}$ exceeded the spacing between the roughness elements in all but the sparsest configurations (13 of the 37 experiments considered). Evidently, the best approximation of lateral cover is $L_{\alpha}$ which produces interactions between sheltered areas and downstream roughness elements for the majority of Marshall's experiments. The implications of these findings are that (i) interactions between roughness elements have been hidden from previous researchers by the longstanding tradition of using $L_{45}$; and (ii) configuration of roughness elements is important for the calculation of the surface shear stress and drag partition. However, we show next that $L_{\alpha}$ cannot be used to replace $L_{45}$.

Recall that total force $F$ acting on $S$ of a rough surface can be partitioned between a force acting on the roughness elements $\left(F_{R}\right)$ and that acting on the substrate surface ( $F_{S}$; in the absence of any roughness elements) such that $F=F_{R}+F_{S}$ (Schlichting, 1936). These forces are divided by $S$ to produce their respective stresses:

$\tau=\rho u_{*}^{2}=\tau_{R}+\tau_{S}$

where $\rho$ is the air density and $u_{*}^{2}$ the square of the wind friction velocity. Shao and Yang (2008) suggested that the total drag should be partitioned in to three components and should include the canopy friction drag $\left(\tau_{C}\right)$. Notably, their drag partition requires $L_{45}$ and the fraction of cover $\left(a_{c}\right)$ as input parameters. Given the fundamental flaw in $L_{45}$ demonstrated previously, we do not pursue this additional component. Following Raupach et al. (1993) $\tau_{S}$ is normalised over the total ground area $S$ rather than the exposed (erodible) ground area $S^{\prime}$. The difference $S$ - $S^{\prime}$ is the total basal area of the roughness elements on $S$. The stress per unit exposed ground area $\tau_{S}^{\prime}$ is

$\tau_{S}^{\prime}=\left(S / S^{\prime}\right) \tau_{S}=\frac{\tau_{S}}{1-\sigma L}$ 
where $\sigma$ is the ratio of roughness-element basal area to frontal area, so that $\sigma L=1-S^{\prime} / S$ is the basal area index (basal area per unit ground area). Following Raupach et al. (1993), the stress partition between the roughness elements and the substrate surface can be derived from any of the shear stress ratios $\tau_{R} / \tau, \tau_{S} / \tau$ or $\tau_{S}^{\prime} / \tau$. Using Marshall's data, the first two shear stress ratios can be obtained directly from the measurements. In contrast, the third shear stress ratio is dependent on the inverse of the basal area index which includes $L$. This ratio was adopted by Raupach et al. (1993) to describe the drag partition:

$R_{t}=\sqrt{\tau_{s}^{\prime} / \tau}$.

If $\tau_{S}^{\prime}$ is calculated with the fixed and incorrect $L_{45}$ then it will not include any interactions between roughness elements and wakes in the drag partition (Figure 2; black diamonds). The values of $L_{45}$ occur mainly $0.0001<L_{45}<0.1$. However, when $\tau_{S}^{\prime}$ is calculated using $L_{\alpha}$, the sheltering is an order of magnitude larger than $L_{45}$ (mainly $0.01<L_{\alpha}<1$ ) and the interactions and therefore the impact of roughness configuration are evident in the broader scatter and values $0>R_{t}>1$ (white square symbols; Figure 2). In other words, all previous wind erosion estimates made using $L_{45}$ are likely to either have been over-estimated (or tuned inappropriately against measurements to achieve the correct sediment flux).

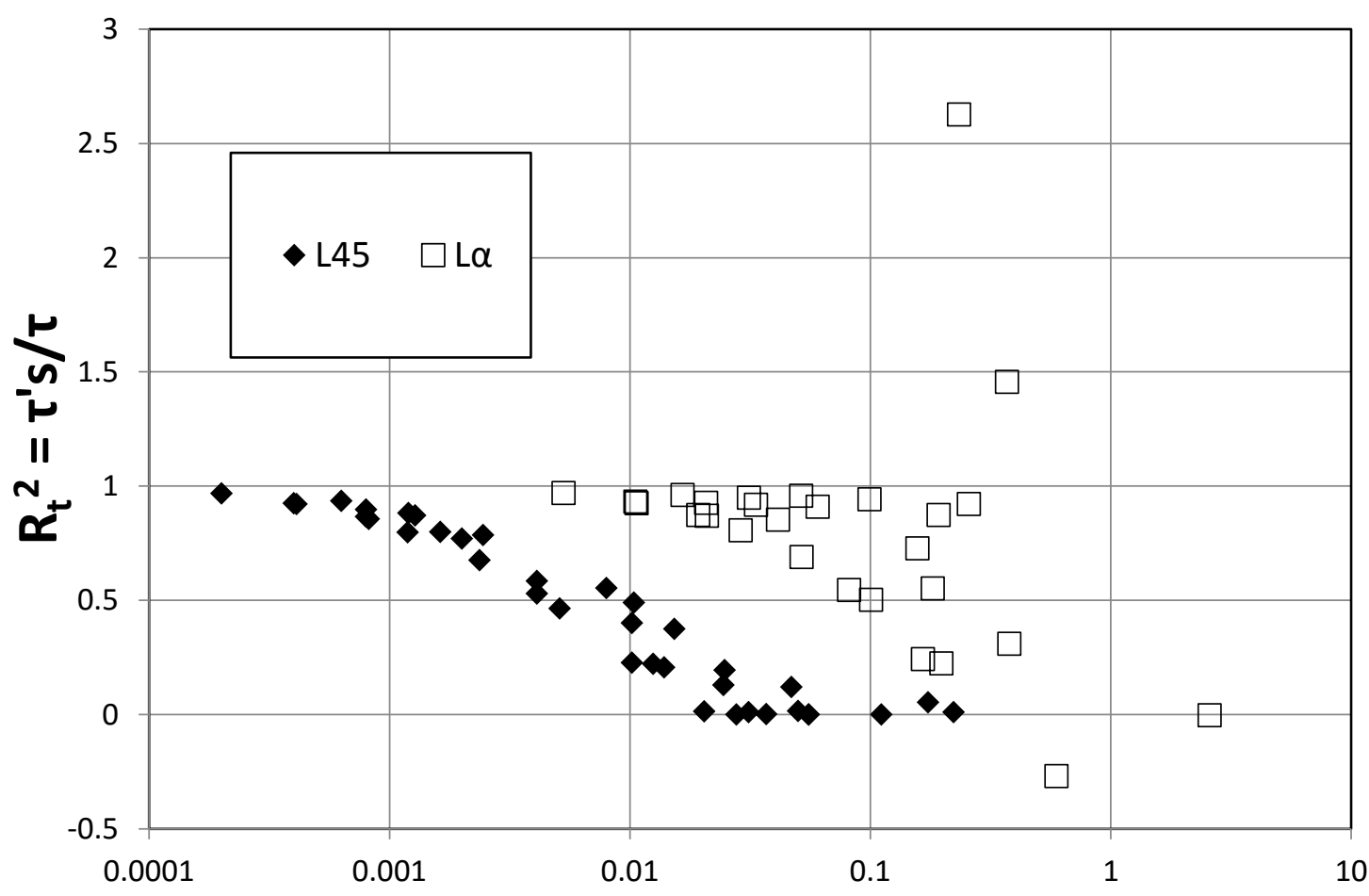

Figure 2. Marshall's (1971) wind tunnel measurements used to calculate lateral cover $\left(L_{45}\right.$ and $\left.L_{\alpha}\right)$ and plotted against the drag partition $R_{t}{ }^{2}$ (so that $R_{t} \leq 0$ can be included) to illustrate the previously hidden effect of roughness configuration.

The influence of roughness element configuration on the drag partition e.g., regular grid, staggered, random or clumped (e.g., Marshall, 1971; Minvielle et al., 2003; Raupach et al., 2006) is masked by the use of $L_{45}$. Equation 12 is invalid when $L_{\alpha} \gg 1$ because when inverted in the basal area index, negative $\tau_{S}^{\prime}$ are produced (Figure 2). Equation 2 is only valid if the length of the sheltered area is truncated by the downstream roughness elements. That is, the length of $A \leq$ roughness element spacing. Consequently, it appears from these results that historically $L_{45}$ has been chosen to ensure that these truncations occur when the spacing of roughness elements in the wind tunnel is less than or equal to the height of the roughness elements (used in Marshall's experiments). These truncations (representing wake interactions) between roughness elements cannot be expressed by the simple 
geometric formulation of $L_{\alpha}$. A finding consistent with Raupach's (1992) scepticism that the model of $L_{45}$ could describe adequately the highly three-dimensional flow amongst roughness elements. We therefore propose that lateral cover $\left(L_{45}\right.$ or $\left.L_{\alpha}\right)$ should be replaced by an alternative, appropriate approach which we describe in the next section.

Okin (2008) avoided the use of $L$ by extending Raupach's (1992) approach to develop a drag decay function over space, dependent on information about the separation between roughness elements. This approach provides the opportunity to include the spatial variation of drag, and the potential to better represent the area-integrated (areal) transport (Webb et al. 2014). To parameterise the model, ground-based measurements of roughness distribution and height are made relatively easily at the plot scale or for small $\left(10 \mathrm{~m}^{2}\right)$ areas. However, these data can become prohibitively expensive to acquire when sampling is required to adequately represent spatial variability particularly over large regions. Collection of these data is therefore often not feasible at broad (regional) scales and requires approximations using remote sensing or other ancillary or indirect information similar to those of $L$, to parameterise the model.

\section{Using shadow to approximate sheltered area interactions and aerodynamic properties}

Chappell and Heritage (2007) introduced the notion of using shadow to approximate sheltered areas and aerodynamic turbulence primarily because of the need to make estimates of sediment transport for heterogeneous roughness across spatial scales (e.g., Marticorena and Bergametti, 1995; Alfaro and Gomez, 1995; Shao, 2001). Chappell and Heritage (2007) were concerned with the anisotropic nature of the aerodynamic turbulence which, for a heterogeneous surface, must be different for different wind directions (Figure 1b). For a given number and object geometry, the $L_{45}$ or $L_{\alpha}$ will be the same but the sheltered area, and shear stress partition, may be quite different. Chappell and Heritage (2007) questioned whether models tested against roughness lengths measured from field wind velocity profiles are indeed valid and suggested that there was a need for a method to independently predict the directional aerodynamic turbulence characteristics across scales. Following Arya (1975) and Raupach (1992), they suggested that the length of a sheltered area behind an isolated obstacle was a function of wind velocity (at a reference height) and roughness element height. Chappell and Heritage (2007) calculated the sheltered area as shadow by invoking relative roughness (common in fluvial hydrology) to approximate the illumination angle. They showed a relation between shadow and wind tunnel estimates of aerodynamic roughness length obtained by Dong et al. (2002).

Chappell et al. (2010) reconstructed the configurations of hemispheroids used to represent surface roughness in the wind tunnel study of Dong et al. (2002) and then illuminated the surfaces for a range of zenith angles (for a given azimuth angle). The approach of Chappell et al. (2010) has a similar physical basis to that described by Raupach (1992). Instead of calculating the projection of the frontal area from its side the same calculation is made from above and can use the projection angle $\alpha$ (Raupach, 1992; Figure 1b). Shadow is sensitive to configuration of roughness objects. In other words, the proportion of shadow will depend on the proximity of objects to each other, their height, width, and the direction of the illumination (continuing the analogy with wind direction).

Following the approach of Chappell et al. (2010), here we reconstructed Marshall's (1971) wind tunnel experiments of regular cylinders using digital elevation models of hemispheroids and illuminated each surface across a range of zenith angles $\left(0-90^{\circ}\right)$. The hemispheroids were used in place of cylinders, the bluff wall of which created an artefact unlikely to be found in reality (Chappell and Heritage, 2007). The ray-casting for a range of illumination angles was viewed at nadir and integrated to approximate the direct beam directional hemispherical reflectance (or black sky albedo $\omega$ ). We used the inverse to reveal the shadow (1- $\omega$ ) and normalised by the black sky albedo of the surface when illuminated and viewed at nadir $\left(\omega_{n}=(1-\omega) / \omega_{0}\right)$. This normalisation approach removed the influence of spectral reflectance on the results. We also calculated $\omega_{n 45}=\left(1-\omega_{45}\right) / \omega_{0}$ to represent the projection at $45^{\circ}, \omega_{n \alpha}=\left(1-\omega_{\alpha}\right) / \omega_{0}$ to represent the projection at $\alpha=U_{h} / u *$ and $\omega_{n 87}=\left(1-\omega_{87}\right) / \omega_{0}$ to represent the projection of $\alpha$ but at a fixed angle of $87^{\circ}$. There is so little variation in $\alpha$ across the large range of Marshall's roughness surfaces that $\omega_{n 87}$ provided a precise approximation of $\omega_{n \alpha}$. We also found that both measures $\left(\omega_{n 87}\right.$ and $\left.\omega_{n^{\alpha}}\right)$ were similar to, but had less variability than, the integration $\omega_{n}$. The $\omega_{n 45}$ was the worst approximation. 
An arising implication which we elaborate in the final section is that future studies (e.g., wind tunnel and field work) can make use of the straightforward relation between illumination angle and at-nadir viewing to approximate the aerodynamic properties. The $\omega_{n}$ provided a measure which adequately represented projections at $\alpha$ and produced the least variation when plotted against the key aerodynamic properties used in wind erosion and dust emission models. It was adopted here because of the relative ease with which it can be replicated by available MODIS products. It was rescaled $\left(\omega_{n s}\right)$ from the normalised range $\left(\omega_{n \min }, \omega_{n \max }\right.$ of a given waveband $\left.v\right)$ to that of the calibration data ( $a=0$ to $b=1$ ) using the following equation:

$\omega_{n s}=\frac{(a-b)\left(\omega_{n}(v)-\omega_{n}(v)_{\max }\right)}{\left(\omega_{n}(v)_{\min }-\omega_{n}(v)_{\max }\right)}+b$.

The relations with the aerodynamic properties are shown in Figure 3.

Although above we recommended avoiding the use of $L_{45}$ in modelling wind erosion, we provide it here for completeness. There is a strong positive relation between $\omega_{n s}$ and $L_{45}$. When $L$ is large the proportion of shadow is large and as $L$ decreases so $\omega_{n s}$ decreases. The $L_{45}$ has values which are only slightly larger than those of $\omega_{n s}$. This small difference is caused by the shadow overlapping part of the downstream roughness elements. The $L_{45}$ has a fixed angle which is designed so that the predicted shelter areas do not interact with the downstream roughness elements even when the spacing between roughness elements is very small (i.e. minimum spacing is set to roughness element height). Even though $L_{45}$ is not projected at the correct angle $\alpha$ it provides a reasonable approximation of the sheltered area when roughness elements (with the same geometry) are regularly spaced as with Marshall's experiments. However, as shown above (Figure 2) $L_{45}$ masks the effect of configuration.

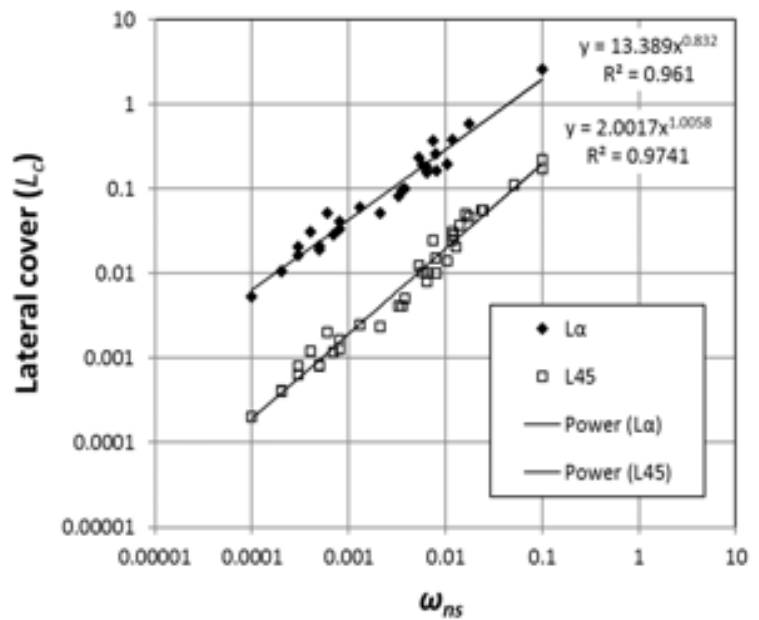

(a)

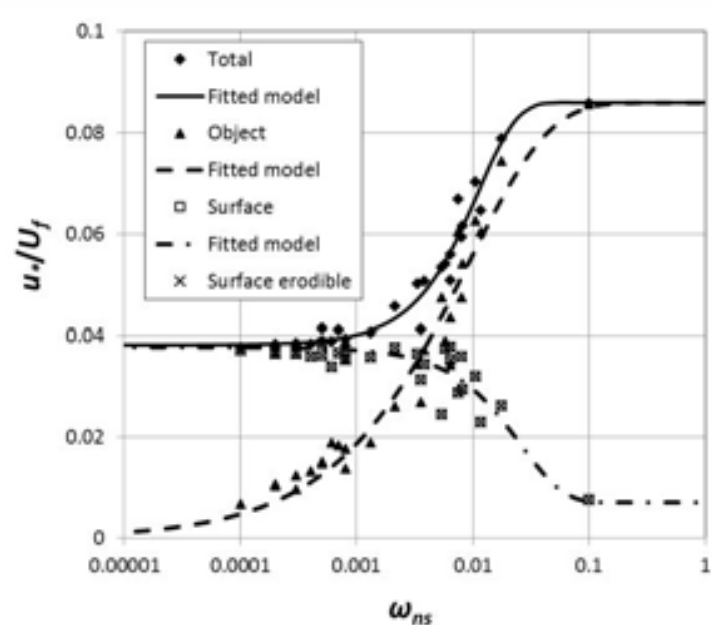

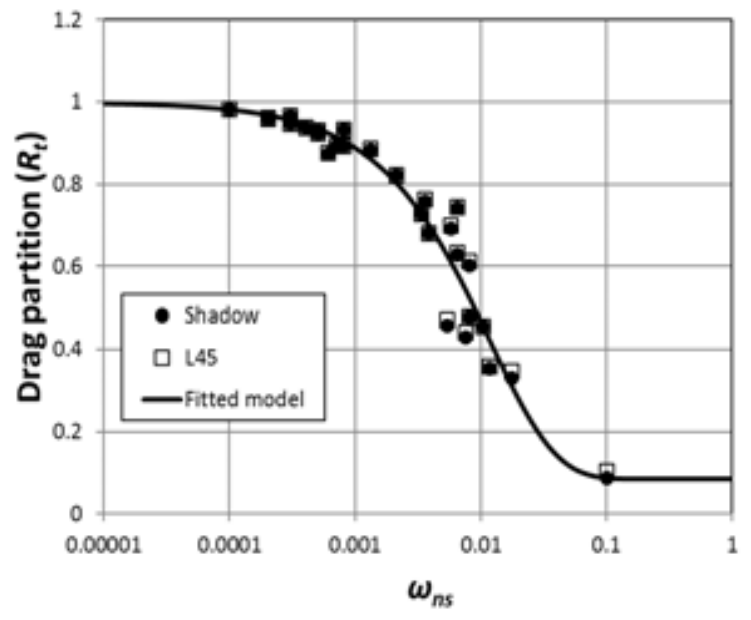

(b)

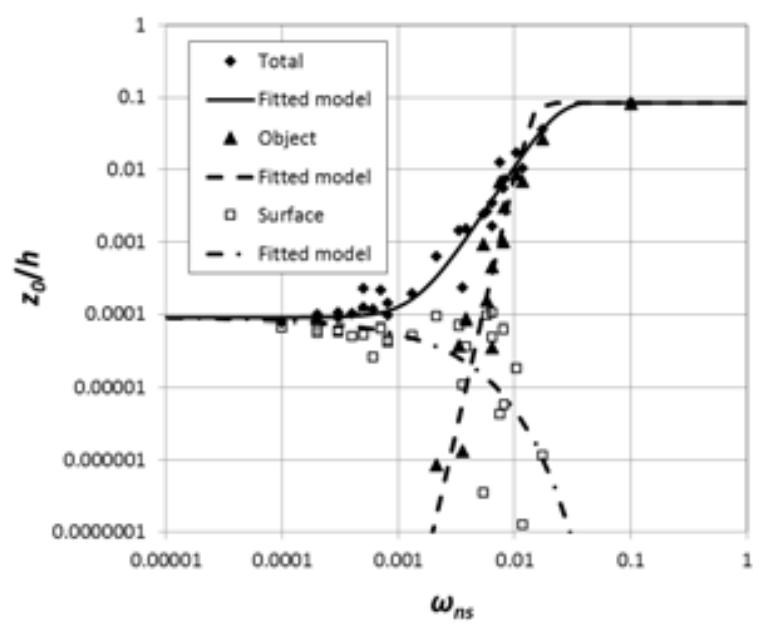

(d)

263 Figure 3. The relations between key aerodynamic properties used in wind erosion and dust emission models and normalised albedo (proportion of shadow). We illuminated each of Marshall's (1971) surfaces across the range of 
zenith angles to approximate the direct beam directional hemispherical albedo (or black sky albedo $\omega$; viewed at nadir). We normalised $\omega$ by the reflectance of the surface, illuminated and viewed at nadir $\left(\omega_{0}\right)$, to remove any spectral influences, used the inverse to reveal the shadow $\omega_{n}=(1-\omega) / \omega_{0}$ and then rescaled $\left(\omega_{n s}\right)$. The key aerodynamic properties include (a) the lateral cover; (b) the drag partition $\left(R_{t}\right)$ derived from Marshall's (1971) data; (c) the wind shear stress scaled by the velocity at a freestream height $\left(u_{*} / U_{f}\right)$; $(d)$ aerodynamic roughness length scaled by the roughness height $\left(z_{0} / h\right)$. Equations of the curves fitted to the data used in $b, c$ and $d$ are provided in the formula in section 4. Note that the cluster of data omitted by Raupach et al. (1993) in their analysis has also been omitted in our analysis.

When we consider the drag partition $\left(R_{t}\right)$ calculated from Marshall's (1971) data using equation 1-2 with $L_{45}$ there is a strong relation with $\omega_{n s}$ (Figure $3 \mathrm{~b}$ ). This is to be expected because of the strong relation between $L_{45}$ and $\omega_{n s}$. Moreover, it suggests that $R_{t}$ can be estimated directly using the shadow at the (land) surface. We showed that $L_{45}$ is incorrect but when $R_{t}$ is calculated using the best approximation $L_{\alpha}$ (Eq. 1) $R_{t}$ cannot be modelled well (Figure 2). Instead we calculated $R_{t}$ using albedo since the exposed area is equivalent to $\omega_{n s}$ and its inverse $1-\omega_{n s}$ is shadow. This enables calculation of the surface shear stress following:

$\tau_{S}^{\prime}=\left(S / S^{\prime}\right) \tau_{S}=\frac{\tau_{S}}{1-\omega_{n s}}$.

We used these new shadow-based estimates of $\tau_{S}^{\prime}$ for Marshall's study to calculate $R_{t}$ following Eq. 9. We then plotted the albedo-derived $R_{\mathrm{t}}$ on Figure $3 \mathrm{~b}$. Notably, for intermediate and dense roughness (large $\omega_{n s}$ equivalent to $L_{45}>0.001$ ) the values of $R_{t}$ calculated using shadow are slightly smaller than those calculated using $L_{45}$. This is because the shadow is correctly representing the larger sheltered area than that estimated using $L_{45}$. Although subtle when plotted in this way, the difference in the values represents the previously hidden influence of roughness configuration on $R_{t}$. The impact is negligible at very small roughness density because the sheltered area is a very small proportion of the total erodible area. Similarly, at very large roughness density the impact is negligible because there is little space between the roughness elements. The model displayed (solid line) was fitted to the $R_{t}$ values calculated using shadow (Eq. 4) using a Levenburg-Marquardt non-linear optimisation (RMSE=0.05839).

There is a strong relation between $\omega_{n s}$ and the measured shear stresses (total $u_{T^{*}}$, objects $u_{R^{*}}$, surface $u_{S^{*}}$ and erodible surface $u_{s^{*}}$ ) scaled by the freestream velocity $U_{f}$ (Figure $3 c$ ) and between $\omega_{n s}$ and the calculated aerodynamic roughness length scaled by roughness element height $\left(z_{0} / h\right.$; Figure $\left.3 d\right)$. In both cases this strong relation is to be expected because of the strong relation between $L_{45}$ and $\omega_{n s}$ and provides the first indication of redundancy in information content which we exploit below. The displayed models (solid lines) were fitted to the data using the same as previous non-linear optimisation (RMSE $=0.0027$ and 0.0064 , respectively). These data show little evidence of the expected reduction in shear stress at large $\omega_{n s}$ (in either $z_{0} / h$ or $u * / U_{f}$ ) due to skimming flow. For consistency with the observations we fitted models which did not include a reduction in shear stress when $\omega_{n s}>0.1$. We also established relations between $\omega_{n s}$ and the shear stresses and between $\omega_{n s}$ and aerodynamic roughness for objects $\left(u_{R^{*}}\right.$ and $\left.z_{0 R} / h\right)$ and surface $\left(u_{S^{*}}\right.$ and $\left.z_{0 S} / h\right)$ scaled by the freestream velocity $\left(U_{f}\right)$ and height respectively. There are two notable findings: (1) erodible surface shear stress $\left(u_{s^{\prime}}\right)$ did not differ from that of the surface shear stress $\left(u_{S^{*}}\right)$ when scaled by $U_{f}$ (differences were evident when not scaled by $U_{f}$ ); (2) surface aerodynamic roughness decreases as lateral cover increases which indicates that the smooth aerodynamic roughness length $\left(z_{0 s}\right)$ is not fixed and constant everywhere as assumed by Marticorena and Bergammetti (1995).

\section{Using shadow to reformulate wind erosion modelling}

\subsection{Reducing the complexity and retaining fidelity of sediment transport}

Our analyses in Section 3 reveal a direct relation between shadow $\left(\omega_{n s}\right)$ and the key aerodynamic properties used in wind erosion and dust emission schemes. The implication here is that such schemes can be simplified without losing any information content and thereby parameterised more effectively. We illustrate this improvement using 
the scheme of Shao et al. (2004) where the horizontal (saltation mass) flux $Q_{h}$ for uniform particles of size $D$ is calculated as:

$Q_{h}\left(U_{f}, u_{T *}, z_{0}, D, L_{45}, w\right)=c_{\text {shao }} \frac{\rho_{a} u_{T *}^{3}}{g}\left(1-\left(\frac{u_{* t}}{u_{T *}}\right)^{2}\right)$.

The parameter $c_{\text {shao }}$ in Owen's (1964) original formulation was found empirically and in typical situations (e.g., soil grain size $D=150 \mu \mathrm{m} ; u_{*}=0.8 \mathrm{~m} \mathrm{~s}^{-1}$ ) $c_{\text {shao }}$ is around 0.8 (Shao et al., 1997), $\rho_{a}$ is the air density $\left(\mathrm{kg} \mathrm{m}^{-3}\right), u_{S^{*}}$ is the surface friction velocity $\left(\mathrm{m} \mathrm{s}^{-1}\right), g$ is acceleration due to gravity $\left(\mathrm{m} \mathrm{s}^{-1}\right)$ and $u_{* t}$ the threshold friction velocity. In theory $u_{S^{*}}$ should be used, but in practice it is not available. Instead $u_{T^{*}}$ is either obtained from an external source such as numerical weather prediction models or similar based on an estimate of the aerodynamic roughness length $z_{0}$. The $u_{T^{*}}$ should be converted to $u_{S^{*}}$ using $R_{t}$

$u_{T *}=u_{S *} / R_{t}$

but in practice this may not occur. We show later in this section, the consequences of using $u_{T^{*}}$ instead of the correct values of $u_{s^{*}}$. Here the $u_{T^{*}}$ scaled by the freestream velocity $\left(U_{f} ; \mathrm{m} \mathrm{s}^{-1}\right)$

$\frac{U_{f}}{u_{T *}}\left(z_{0}, L_{45}\right)=\frac{1}{k} \ln \left(\frac{d e l}{z_{0}}\right)$,

is estimated using von Kármán's constant $(k)$, del the approximation of boundary layer depth provided by Wooding et al. (1973; p. 295) for use with Marshall's data and roughness height $h$ and breadth $b$.

$\operatorname{del}\left(L_{45}\right)=3.3+15\left(L_{45}\left(\frac{h}{b}\right)^{0.38}\right)^{0.43}$.

We estimated $z_{0}$ scaled by $h$ using the empirical relation with $L_{45}$ suggested by Marticorena et al., (1997) and updated by Marticorena et al. (2006)

$\log \left(\frac{z_{0}}{h}\right)=\left\{\begin{array}{ll}1.31 \log \left(L_{45}\right)+0.66 & L_{45}<0.045 \\ -1.16 & L_{45} \geq 0.045\end{array}\right\}$.

The $u_{* t}$ is calculated as the bare soil threshold friction velocity $u_{* t s}(D)$ adjusted by the Raupach et al. (1993) drag partition correction $R_{t}\left(L_{45}\right)$ and soil moisture $(w)$ via the function $H(w)$

$u_{* t}\left(D, L_{45}, w\right)=\frac{u_{* t s}(D) H(w)}{R_{t}\left(L_{45}\right)}$.

The $u_{* t s}$ of a given $D$ includes $A_{N}$ a scaling coefficient, $\rho_{p}$ is the particle density $\left(\mathrm{kg} \mathrm{m}^{3}\right), g$ acceleration due to gravity $\left(\mathrm{m} \mathrm{s}^{-1}\right), \Gamma$ is a parameter accounting for the cohesive force $\left(\mathrm{kg} \mathrm{s}^{-2}\right)$

$u_{* t s}(D)=\left(A_{N}\left(\frac{\rho_{p} g D}{\rho_{a}}+\frac{\Gamma}{\rho_{a} D}\right)\right)^{-0.5}$.

The $R_{t}\left(L_{45}\right)$ includes parameters for the $\sigma_{v}$ the ratio of vegetation roughness element basal area to frontal area, $m_{v}$ accounts for the non-uniformity of the surface stress, $\beta_{v}$ is the ratio of vegetation roughness element to surface drag coefficients (Raupach et al., 1993)

$R_{t}\left(L_{45}\right)=\left(1-\sigma_{v} m_{v} L_{45}\right)^{-0.5}\left(1+m_{v} \beta_{v} L_{45}\right)^{-0.5}$.

A straightforward function $H$ (dimensionless) was proposed by Shao et al., (1997) to account for the volumetric soil moisture content $w\left(\mathrm{~m}^{3} \mathrm{~m}^{-3}\right)$

$H(w)=e^{22.7 w} w \leq 0.03$.

Details of this scheme and its similarity with the other commonly used scheme of Marticorena and Bergametti (1995) can be found in Darmenova et al. (2010). The estimate of the total shear stress $u_{T^{*}}$ requires information about the freestream wind velocity $\left(U_{f}\right)$ and the aerodynamic roughness length (which itself requires information 
on its scaling height $z_{0} / h$ ). Often, $u_{T^{*}}$ is established independently in an atmospheric model and with no connection to the aerodynamic roughness used in the wind erosion scheme. Here we estimated $z_{0} / h$ and then estimated $u_{T^{*}} / U_{f}$ accordingly.

We reduce the number of parameters in the above scheme by using the common relation with $\omega_{n s}$ and thereby establish consistency between the aerodynamic properties and avoid disconnecting $u_{T^{*}}$ from $z_{0} / h$. Furthermore, we avoid the need for $z_{0} / h$ and use the model parameters (assuming they too are fixed) of the relation between $u_{T^{*}} / U_{f}$ and $\omega_{n s}$

$\frac{u_{T *}}{U_{f}}\left(\omega_{n s}\right)=0.0497\left(1-\frac{e^{-\omega_{n s}{ }^{1.326}}}{0.0027}\right)+0.038$

Perhaps most importantly, the drag partition scheme of Raupach et al. (1993), with its difficult to estimate parameters and reliance on the erroneous values of $L_{45}$, can be replaced with the relation between $R_{t}$ and $\omega_{n s}$ and constants to represent all scales of the drag partition

$R_{t}\left(\omega_{n s}\right)=0.9516\left(\frac{e^{-\omega_{n s}{ }^{1.1869}}}{0.0039}\right)+0.048$.

This means that $u_{* t}$ is no longer a function of $L_{45}$ and instead is a function of $\omega_{n s}$

$u_{* t}\left(D, \omega_{n s}, w\right)=\frac{u_{* t s}(D) H(w)}{R_{t}\left(\omega_{n s}\right)}$,

which we show in the next section makes an important difference to the estimates of $Q_{h}$.

The complexity of the model may be reduced still further by estimating $Q_{h}$

$Q_{h}\left(U_{f}, D, \omega_{n S}, w\right)=c_{\text {Shao }} \frac{\rho_{a} u_{S *}^{3}}{g}\left(1-\left(\frac{u_{* t s} H(w)}{u_{S *}}\right)^{2}\right)$,

simplifying

$\frac{u_{* t}}{u_{T *}}=\frac{u_{* t S} H(w) / R_{t}}{u_{S *} / R_{t}}=\frac{u_{* t s} H(w)}{u_{S *}}$,

estimating directly the shear stress at the soil surface $\left(u_{s^{*}}\right)$

$\frac{u_{S *}}{U_{f}}=0.0311\left(\frac{e^{-\omega_{n s}}{ }^{1.131}}{0.016}\right)+0.007$,

and the bare soil threshold friction velocity $\left(u *_{t s}\right)$ as before.

This last reduced complexity (shadow) model (Eqs. 23-25) no longer requires the threshold friction velocity $u_{*}$ and thereby the Raupach et al. (1993) drag partition $R_{t}\left(L_{45}\right)$ (Eq 17) is also not used. Conceptually, this model is consistent with that employed by Okin (2008) and Webb et al. (2014).

\subsection{The significance of using surface shear stress in sediment transport modelling}

We calculated horizontal flux $\left(Q_{h}\right)$ using $u_{T^{*}}$ and $u_{s^{*}}$ separately in three different ways using: (1) Marshall's (1971) aerodynamic measurements; (2) the traditional approach following Shao (2004) and (3) the shadow-based approach. For the purpose of illustration, we followed the approach of Darmenova et al. (2010) and used values they suggested for the roughness parameters in the Raupach et al. (1993) drag partition scheme $\left(\beta_{v}=202 ; \sigma_{v}=\right.$ $1.45 ; m_{v}=0.16$; model 1$)$. For simplicity, the values of the other parameters were fixed in the three approaches including setting $U_{f}=20.3 \mathrm{~m} \mathrm{~s}^{-1}, D=63 \mu \mathrm{m}, A_{N}=0.0123, \rho_{p}=2650 \mathrm{~kg} \mathrm{~m}^{-3}, c_{\text {shao }}=1, \rho_{a}=1.23 \mathrm{~kg} \mathrm{~m}^{-3}, g=9.81$ $\mathrm{m} \mathrm{s}^{-1}, \Gamma=1.65 \times 10^{-4} \mathrm{~kg} \mathrm{~s}^{-2}, H(w)=1$. For simplicity (in equation 13 ) we set $h=0.0254 \mathrm{~m}$ to the height of the roughness elements in Marshall's (1971) experiments and $b=0.05 \mathrm{~m}$ which was the average breadth of the roughness elements used. Setting these parameters to the values of Marshall's data ensured that the range of horizontal mass flux using $L_{45}$ was similar to that produced using $\omega_{n s}$. 
Figure 4a shows the potential fluxes (circles) using $u_{T^{*}}$. At very sparse roughness the flux based on Marshall's experiments is predicted at around $0.05 \mathrm{~g} \mathrm{~m}^{-1} \mathrm{~s}^{-1}$ and as roughness increases the flux increases at an accelerating rate and reaches a maximum flux around $L_{45}=0.05$ before decreasing sharply to $0 \mathrm{~g} \mathrm{~m}^{-1} \mathrm{~s}^{-1}$. The model based on $L_{45}$ (dashed line) shows flux increasing rapidly as lateral cover increases and then decreases slowly. The shadowbased model (solid line) passes through the symbols (is not fitted), reaches a maximum at an $L_{45}$ similar to the flux based on Marshall's experiments and decreases rapidly.

Figure $4 \mathrm{~b}$ shows predicted fluxes and models using $u_{s^{*}}$. At very sparse roughness there is little difference in flux estimated using either $u_{T^{*}}$ (Figure $4 a$ ) or $u_{s^{*}}$. However, as lateral cover increases flux calculated using Marshall's measurements decreases (circles). The model based on shadow passes through the symbols (not fitted). By comparison with the maximum flux in figure 4 a modelled sediment flux is ten times smaller using $u_{S^{*}}$. The model based on $L_{45}$ (model 1 ) shows flux at around 2.5 times larger than the shadow model and describes increasing flux as lateral cover increases. We replaced the values of the Raupach drag partition parameters (model 1 ) with those described in Raupach et al. (1993; $\beta_{v}=170 ; \sigma_{v}=2 ; m_{v}=1$; model 2). The sediment flux reduced and was similar to that of the shadow model. The difference in Raupach drag partition model parameter values evidently explained most of the deviation from sediment flux using Marshall's data and the shadow model. The remaining variance was due to approximations in $z_{0} / h$ to obtain $u_{T^{*}}$ (Eqs. 12-14).

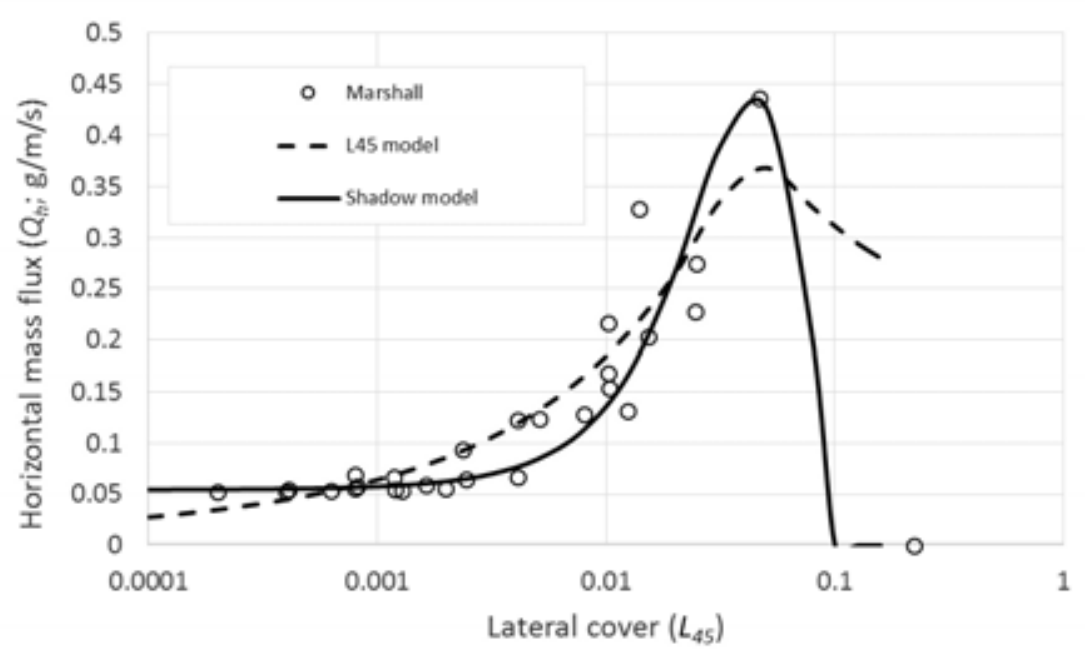

(a)

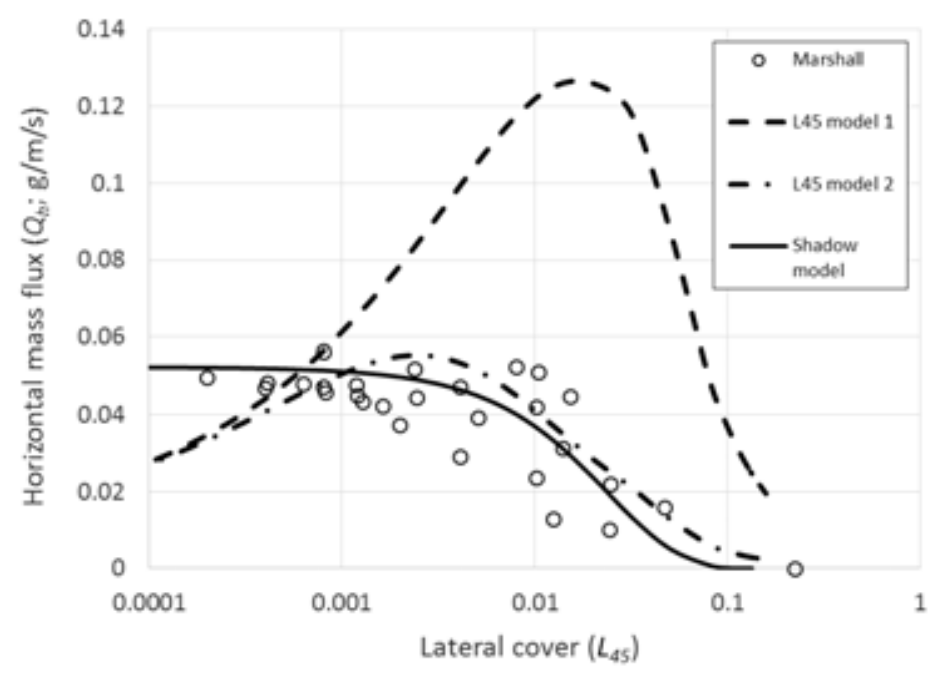

Figure 4. Horizontal flux estimated using the model of Shao et al. (2004) with the aerodynamic measurements from Marshall's experiments (circles), the traditional lateral cover $\left(L_{45}\right)$ and the new approach using shadow $\left(\omega_{n s}\right)$ with $u_{T^{*}}$ (a) and $u_{S^{*}}$ (b) plotted against flux. The flux model based on $L_{45}$ used Raupach (1992) drag partition parameters fixed at $\beta_{v}=202 ; \sigma_{v}=1.45 ; m_{v}=0.16$ (model 1 ) following Darmenova et al. (2010) and fixed at 
$\beta_{v}=170 ; \sigma_{v}=2 ; m_{v}=1$ (model 2) following Raupach et al. (1993). The shadow model used the previously

Using $u_{T^{*}}$ in these calculations of flux implies that sparse vegetation cover promotes flux to such an extent that it is larger than under bare conditions. However, flux decreases exponentially using $u_{s^{*}}$ as $L_{45}$ (or $\omega_{n s}$ ) increases. Notably, between the two approaches there is no difference in the values of the terms $\left(u_{*} / u_{T^{*}}\right)^{2}$ or $\left(u_{*_{t}} / u_{s^{*}}\right)^{2}$ used in $Q_{h}$. The absence of difference demonstrates that the drag partition is working correctly when using measured shear stress or when using the drag partition scheme which closely approximates that of Marshall's $R_{t}$ data. These findings instead suggest that when the drag partition is correct, previous studies which used $u_{T^{*}}$ within a rough canopy (e.g., wind velocity profile in a vegetated area) have considerably over-estimated flux (also demonstrated by Webb et al., 2014). However, outside a rough canopy (e.g., over sand on dunes) $u_{S^{*}} \approx u_{T^{*}}$ and hence the use of $u_{T^{*}}$ in the transport equation will be adequate for estimating the correct flux. We return to these implications in the final section. Similarly, these findings show that when an incorrect estimate of the wind friction velocity is used with a drag partition scheme, the flux may be considerably over-estimated. Given the sensitivity of the results to either adjustments of $u_{T^{*}}$ or to the vagaries of the correct parameterisation of $R_{t}$, it seems prudent to avoid these terms completely by using the shadow model (Eqs. 23-25).

\subsection{A empirical albedo-based sediment transport model}

Notably, when we changed particle size $50 \mu \mathrm{m}<D<500 \mu \mathrm{m}$ (keeping $\rho_{p}$ constant) in the previous experiments with $u_{s^{*}}$ (Figure $4 \mathrm{~b}$ ) we found that there was almost no difference in flux using either $L_{45}$ or shadow. We investigated the shadow model for different $U_{f}$ and $D$ and found that the flux estimates were sensitive mainly to $U_{f}$. Consequently, we tried to model flux using $\omega_{n s}$ and $U_{f}$. We used the same as previous Levenberg-Marquardt non-linear optimisation to fit (RMSE $=0.0088 \mathrm{~g} \mathrm{~m}^{-1} \mathrm{~s}^{-1}$ ) the following exponential model based on $\omega_{n s}$ to the flux calculated from Marshall's data (Figure 5)

$Q_{h}(D)=m\left(\exp \left(-\frac{\omega_{n s}{ }^{1.48}}{p}\right)\right)$,

where $m=0.00044 U_{f}^{2}-0.0091 U_{f}+0.0476$ and

$p=0.0001 U_{f}^{0.85}$.

The magnitude parameter $m$ varied with $U_{f}$ and was fitted best by a quadratic polynomial $\left(R^{2}=0.93\right)$ and the shape parameter $p$ varied with $U_{f}$ and was fitted best $\left(R^{2}=0.99\right)$ with a power function. The power used to raise $\omega_{n s}$ was fixed at the constant 1.48. The implication of this modelling is that horizontal mass flux requires only precise estimates of $\omega_{n s}$ and $U_{f}$, and that $u_{*}$ is not required. We will discuss these implications in the final section. Note the discrepancy in calculated flux at large values (small $\omega_{n s}$ ). 


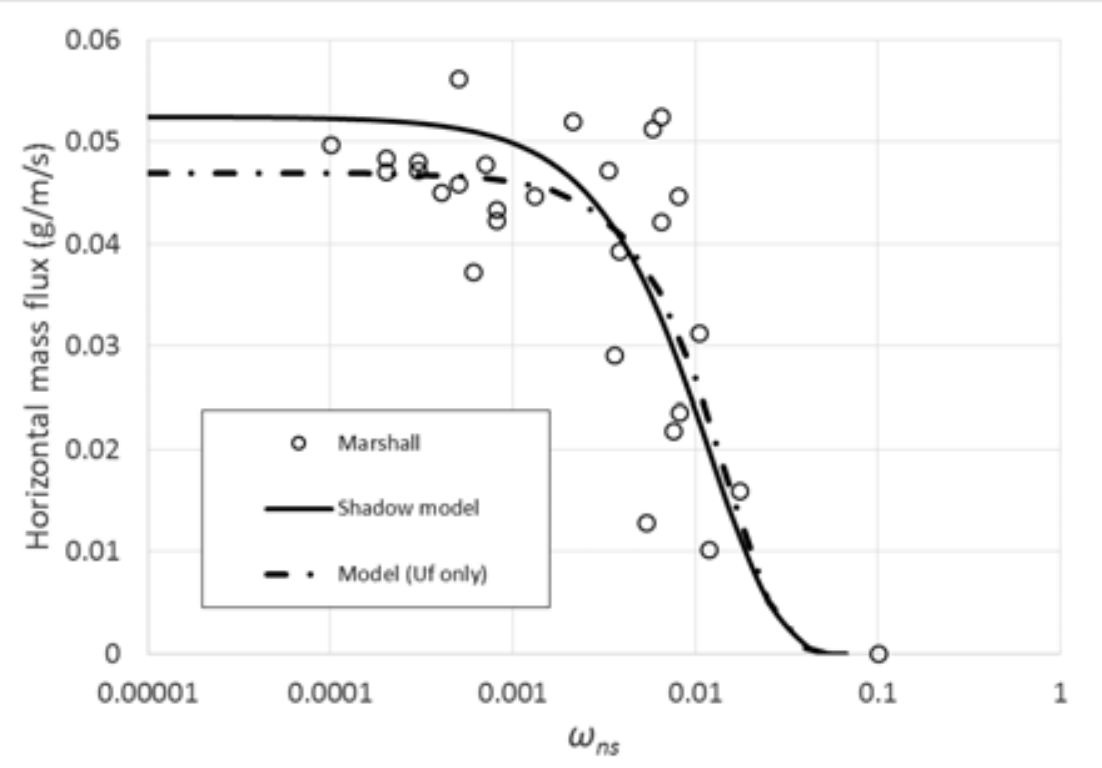

Figure 5. Horizontal flux estimated using the scheme of Shao et al. (1996) with the aerodynamic measurements from Marshall's experiments (circles), the new approach using the shadow model (solid line) and the empirical model based on $U_{f}$ (Equation 8).

The flux predicted using Marshall's experiments was based on measured $u *$ and did not include $L_{45}$. The variability in fluxes for a given lateral cover (or $\omega_{n s}$ ) therefore cannot be attributed to the influence of roughness configuration unless it is inherent in the measurements. The variability in predicted fluxes is most likely explained by the precision of the wind tunnel experiments (measurements, wind speed variation etc.) and the use of squared and cubed terms in the transport equation. Consequently, the scatter provides the uncertainty (average RMSE $=0.0088 \mathrm{~g} \mathrm{~m}^{-1} \mathrm{~s}^{-1}$ for the current simulations) and the most likely limit of detectable change in areaintegrated (areal) sediment flux over space and time. It is very unlikely that a similarly small uncertainty in areal flux could be obtained in current field measurements, particularly those measured at one or even few locations within a given area. We discuss the implications of this finding in the final section. In the next section we show how the direct calibrations of $\omega_{n s}$ with aerodynamic properties improve the estimation of wind erosion and how the aerodynamic properties can be estimated across scales of variation using $\omega_{n s}$.

\section{Using shadow to estimate wind erosion across scales of variation}

\subsection{Retrieving aerodynamic properties across scales of variation}

The $\omega_{n s}$ can be retrieved directly over an area, across a range of scales ( $\mathrm{mm}$ to $\mathrm{km}$ ) because when albedo is integrated across scales it is linearly additive. Albedo is available from a range of extant approaches and platforms e.g., wind tunnel or field measurements from pyranometers and model estimates from angular reflectance on aircraft or satellites. Of perhaps the greatest opportunity and that which is illustrated here, is to use albedo products from NASA's Moderate Resolution Imaging Spectroradiometer (MODIS). The global nature of the MODIS albedo product (MCD43A1), its moderate resolution in space $(500 \mathrm{~m})$ and time $(8$ days) and data archive from the year 2000-present, enables a $>15$-year database of $\omega_{n s}$ from which the key aerodynamic properties can be estimated for modelling, mapping and monitoring of global wind erosion, investigating the impact of global land management and for constraining Land Surface Models, amongst other applications.

The operational MODIS bi-directional reflectance distribution function (BRDF) albedo algorithm makes use of a kernel-driven linear BRDF model, which relies on the weighted sum of an isotropic weighting parameter $\left(f_{\text {iso; }}\right.$; dimensionless) and two functions (or kernels) with parameters of viewing and illumination geometry (Roujean et al., 1992). The parameter $f_{\text {iso }}$ represents the spectral contribution. The kernel weights that best fit the majority situation are selected (Lucht et al., 2000; Schaaf et al., 2002) and used to produce the at-nadir BRDF-adjusted reflectance (NBAR) product (MCD43A4). Once an appropriate BRDF model has been retrieved, integration over all 
view angles results in a directional-hemispherical 'black-sky' albedo called the direct beam (dir). It is a spectradependent $(v)$ direct beam albedo $\omega_{\operatorname{dir}}(\theta, v)$ and a function of solar zenith angle $\theta$ in the absence of a diffuse component. For a given waveband $v$ we assume that the MODIS $\omega_{\text {dir }}\left(0^{\circ}, v\right)$ and integration of view angle information was reciprocal to our ray-casting model which uses at-nadir view angle and integrates illumination angle information. The shadow is the inverse $1-\omega_{d i r}\left(0^{\circ}, v\right)$ and we removed the spectral influence by normalising it with $f_{\text {iso }}$ :

$\omega_{n}=\frac{1-\omega_{\operatorname{dir}}(\theta, v)}{f_{\text {iso }}(v)}=\frac{\omega_{\operatorname{dir}}(\theta)}{f_{\text {iso }}}$

We found that there is little difference in $\omega_{n}$ between MODIS bands and adopted MODIS band 1 (B1). To enable the MODIS $\omega_{n}$ to predict the aerodynamic properties we needed to make it consistent with the calibration relations established from the ray-casting and Marshall's (1971) wind tunnel. So we translated and scaled the data $\left(\omega_{n s}\right)$ using Eq. 8.

We processed the current MODIS (MCD43A1) global archive to estimate $\omega_{n s}\left(f_{i s o}, v_{B 1}\right)$ and to predict aerodynamic properties following the approach outlined above. We illustrate the information content of these aerodynamic properties by displaying maps of the spatial variation of the aerodynamic properties (Figure 6). Firstly, we noted that the maps contained almost identical information (for the selected day). This redundancy is consistent with the reduced complexity we demonstrated in the calculation of mass flux (Eqs. 23-25). Regardless of property, there is a clear distinction between those areas which have small aerodynamic roughness (at $500 \mathrm{~m}$ pixel scale) and thereby are most susceptible to mass flux, and those which are not. The regions with e.g., the smallest $u_{s^{*}} / U_{f}$ are in the highest latitudes where the land surface is covered in snow and ice. Regions with the smallest aerodynamic roughness uncovered by snow and ice are in a mega-region which extends across North Africa, the Arabian Peninsula, across Persia, and into northern western China and Mongolia. This mega-region is 'Barren or Sparsely Vegetated' following the MODIS global land cover classification. Regions which have slightly larger aerodynamic roughness include most of Australia, the southern and eastern countries in Africa, most of Argentina and northern Chile, coastal Peru, northern Mexico, western USA and southern Canada. These regions are associated with the MODIS land cover class 'Open Shrublands'. Furthermore, many parts of Europe include small aerodynamic roughness e.g., southern Portugal, most of Spain, Turkey, northern France, western Germany, south-eastern UK and Iceland. These regions are classified as either Cropland or Grassland. Many of these regions have well documented wind erosion (Goossens et al., 2001). However, the prevailing thinking is that wind erosion is caused by the regions' erodibility i.e., silt- and sand-sized material available for transport (e.g., EU project Wind Erosion on European Light Soils: WEELS). We know that particle size may have very little influence on horizontal mass flux. Our results therefore demonstrate that the main influences on horizontal mass flux in these regions is their small aerodynamic roughness (notwithstanding the influence of free stream wind velocity and soil moisture). There is much similarity in the aerodynamic roughness of these European regions despite cutting across considerable differences in soil type and specifically soil colour. The similarity in the aerodynamic roughness provides additional confirmation that the normalisation by $f_{\text {iso }}$ has successfully removed the influence of spectral information. 

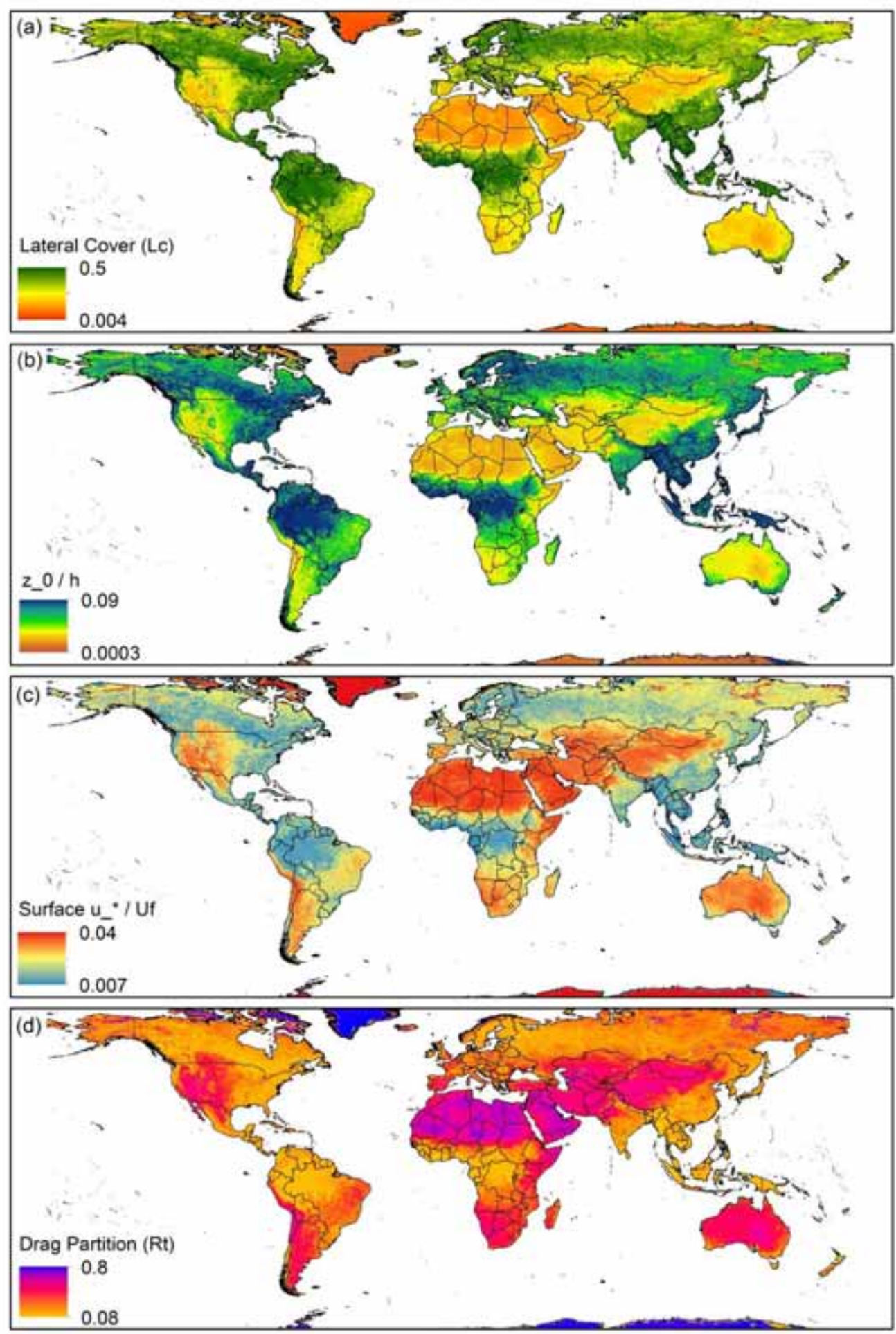

Figure 6. Maps of (a) lateral cover $\left(L_{45}\right),(b)$ aerodynamic roughness length scaled by surface height $\left(z_{0} / h\right),(c)$ surface friction velocity scaled by freestream wind velocity $\left(u_{s^{*}} / U_{f}\right)$ and (d) drag partition $\left(R_{t}\right)$ from MODIS (MCD43A1; 22 September 2009) using the established methodology.

\subsection{Exposing the limitations of $L_{45}$ in sediment transport modelling}

To illustrate the ability of the shadow-based approach for estimating sediment flux across scales of variation, we selected 33 pixels $(500 \mathrm{~m})$ from across the main agro-ecological systems in Australia to model wind erosion and to subsequently monitor (every 8 days) wind erosion 2000-present. Some of these pixels are located in highly vegetated (tropical and temperate) regions where little or no wind erosion occurs. We selected four of the available 33 pixels for detailed spatial and temporal analysis (Figure 7). 


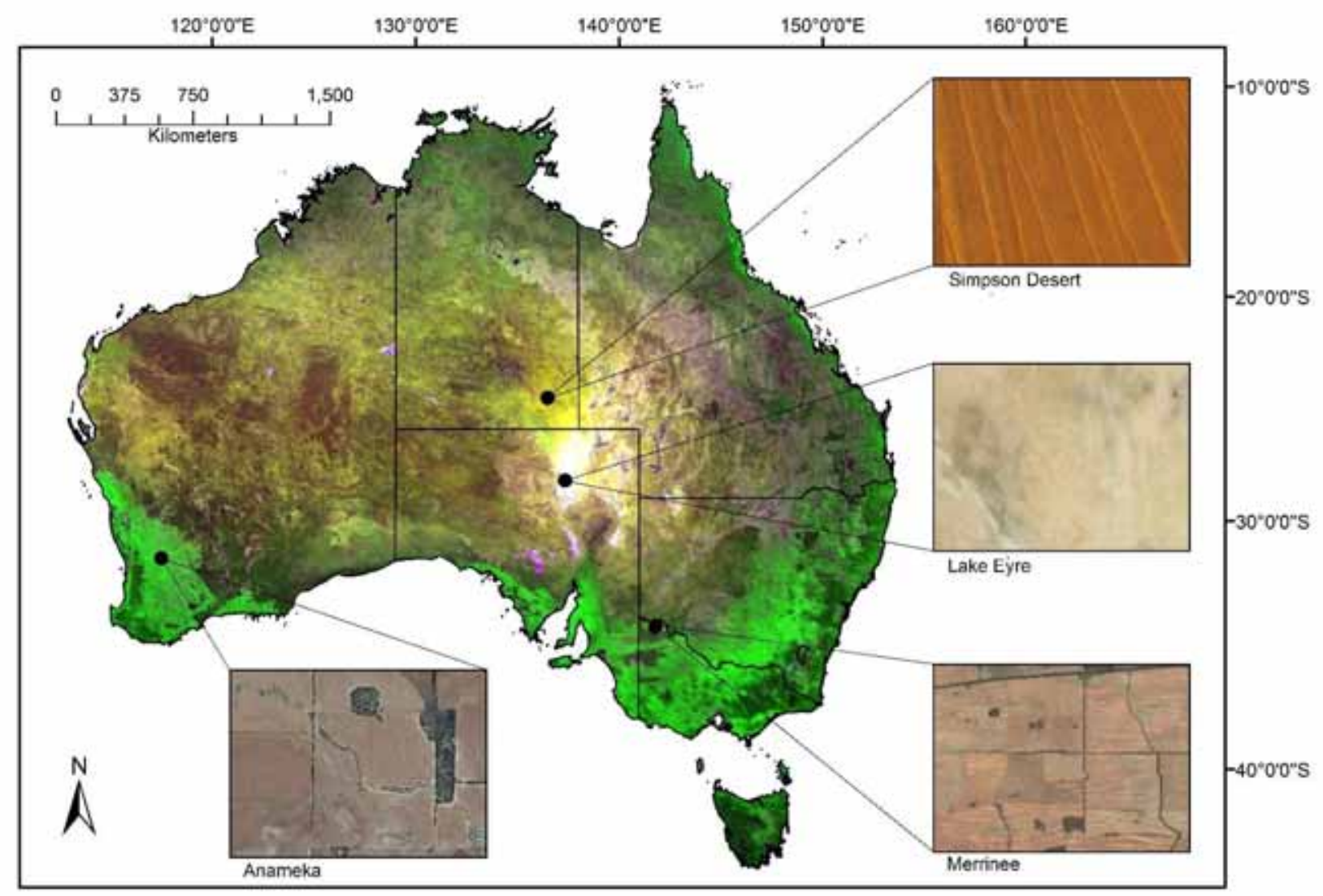

Figure 7. Locations of $500 \mathrm{~m}$ pixels in Australia chosen to consider change over time. We focused on a desert site with little ground cover and loose sand (Simpson, Northern Territory), a cultivated site covered with a crop until harvest and then grazed by sheep (Anameka, Western Australia), a site in a mainly dry playa (Lake Eyre, South Australia) and another cultivated site in the Mallee region where wind erosion occurs frequently (Merrinee, New South Wales). The inset images are approximately $1.5 \mathrm{~km}^{2}$ to illustrate the heterogeneity in land surface erodibility that occurs between $500 \mathrm{~m}$ pixels.

For the entire period (ca 25,000 days) we retrieved the aerodynamic properties from MODIS (MCD43A1) and estimated the horizontal mass flux using the Shao scheme based on (i) $L_{45}$ (Eqs. 10-18) and (ii) $\omega_{n s}$ (Eqs. 23-25). The bare soil threshold friction velocity $\left(u_{* t s}\right)$ was common to both approaches and was fixed over space and time. We ensured $u_{S^{*}}$ was used in the former approach where $u_{T^{*}}$ was estimated from $z_{0} / h$ by adjusting it using $R_{t}$. To ensure compatibility between the two approaches we replaced the parameter values used by Darmenova et al. (2010) for Raupach's drag partition scheme, with those fixed at $\beta_{v}=170 ; \sigma_{v}=2 ; m_{v}=1$ (model 2) following Raupach et al. (1993).

In the first approach we estimated lateral cover following Shao $\left(2004 ; C L_{45}\right)$ using the relation:

$$
C L_{45}=-c \ln \left(1-a_{c}\right)
$$

where $c$ is an empirical coefficient which represents the shape of the vegetation type and $a_{c}$ is the cover fraction and may be represented using photosynthetic cover. In the Shao scheme the parameter $c=0.35$ was determined empirically from a field in Australia with a crop stubble (Shao et al., 1996). In practice, this parameter value is kept constant in the absence of any other information about vegetation type (Darmenova et al., 2010). We calculated $C L_{45}$ from Marshall's data and plotted it against $L_{45}$ (Figure 8). We assumed that values of $L_{45}$ were correct for $C L_{45}$ and inverted Eq. 31 to estimate variable $c$. The results show that $C L_{45}$ estimated by keeping the shape coefficient fixed (symbols), is a reasonable approximation (with bias) of a varying shape coefficient (thick line). 


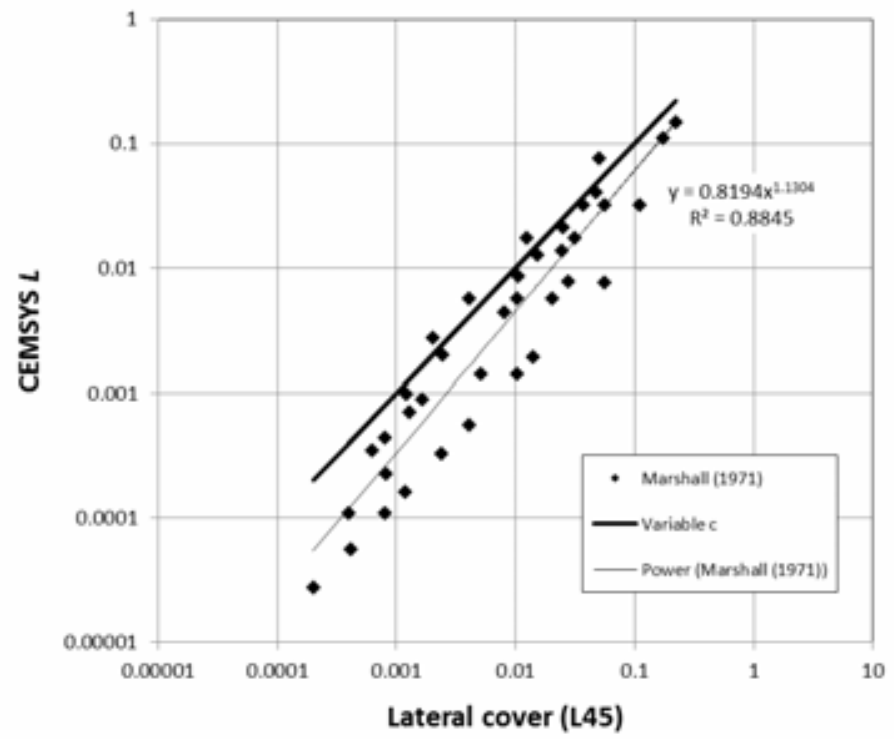

Figure 8. Lateral cover $\left(L_{45}\right)$ of Marshall's (1971) roughness configurations against $L$ estimated using fractional cover.

537 In our calculation of flux we estimated $a_{c}$ using only the photosynthetic fraction of vegetation. When $a_{c}$ was 0 , we set a lower limit of $L_{45}=0.0001$.

Figure 9a shows that there is some similarity in the horizontal mass flux between the two approaches. However, across the range of flux estimated by the shadow model there is a limited range of flux estimated by the model based on $L_{45}$. The horizontal lines of symbols are artefacts of the discontinuities and lack of resolution which exist in the fractional cover data used in Eq. 31 and the bias we described in Figure 8. To elucidate the sources of difference between the flux estimates we plotted $L_{45}$ against flux estimated using the $L$-based approach and the shadow-based approach (Figure 9b). The pattern of flux predicted using shadow was similar to that of the flux calculations based on Marshall's aerodynamic measurements (Figure 5). This is to be expected since there is an almost 1:1 relation between $L_{45}$ and $\omega_{n s}$. However, using the $L$-based approach the majority of values exceeded $L_{45}=0.1$ and the magnitude of $L_{45}$ was larger than the shadow model. In contrast, the shadow-based model had the majority of values between $0.001<L_{45}<0.1$.

In the $L$-based model the estimates of $L_{45}$ have a strong influence on flux because they are used to estimate $z_{0} / h$ and $u_{*}$. To determine the extent to which $L_{45}$ was causing the difference in horizontal flux (under the given simulation conditions), we replaced it with estimates of $L_{45}$ using $\omega_{n s}$. This replacement removed the dependency of $L_{45}$ on fractional cover estimates and a relation emerged between the flux estimates (Figure 9c). The discontinuity in the flux estimates is due to the piecewise model of $z_{0} / h$ (Eq. 14). These differences may be even larger in practice when the wind friction velocity $(u *)$ is obtained from an atmospheric model, with roughness separate (disconnected) from the wind erosion scheme. We plotted $L_{45}$ against flux and although little changed in the magnitude the distribution of data were similar. We proceeded to replace the other aerodynamic model parameters $\left(R_{t}, z_{0} / h\right.$ and $\left.u_{T^{*}}\right)$ in the same manner. The changes to flux were very minor and are not shown here. A final replacement of $u_{T^{*}}$ confirmed that the models were performing as expected because the fluxes for each approach matched exactly and the plot of $L_{45}$ against flux showed flux which coincided exactly for both models. 


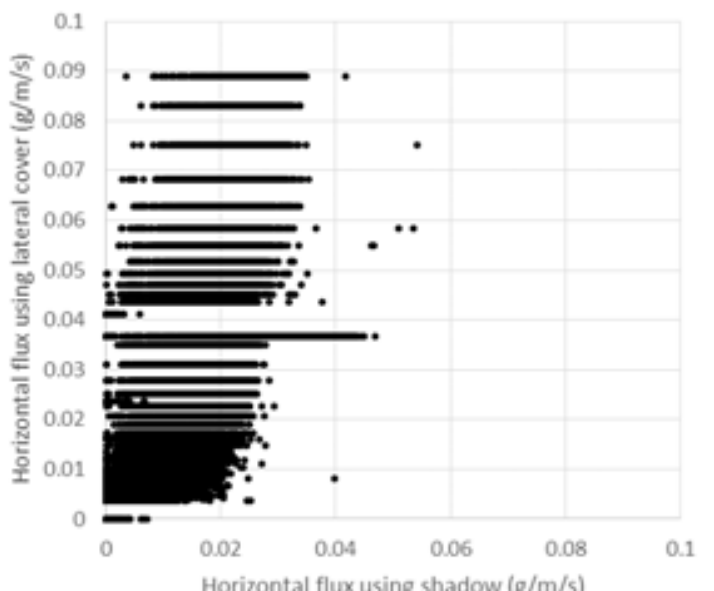

(a)

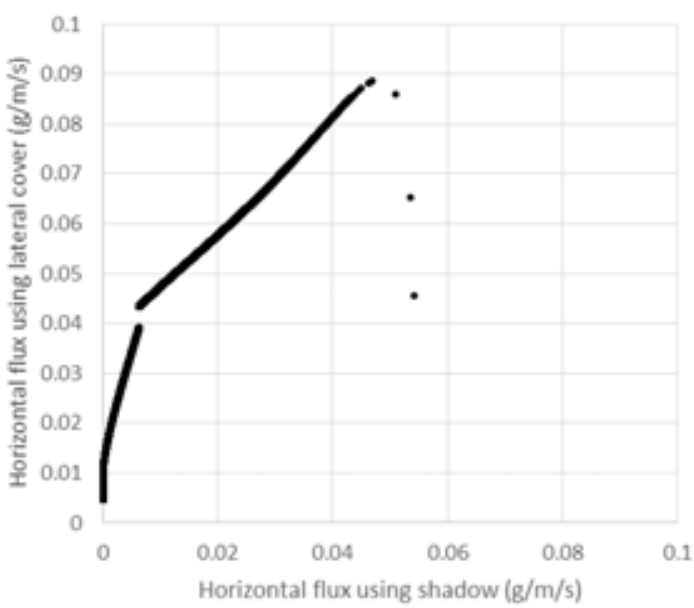

(c)

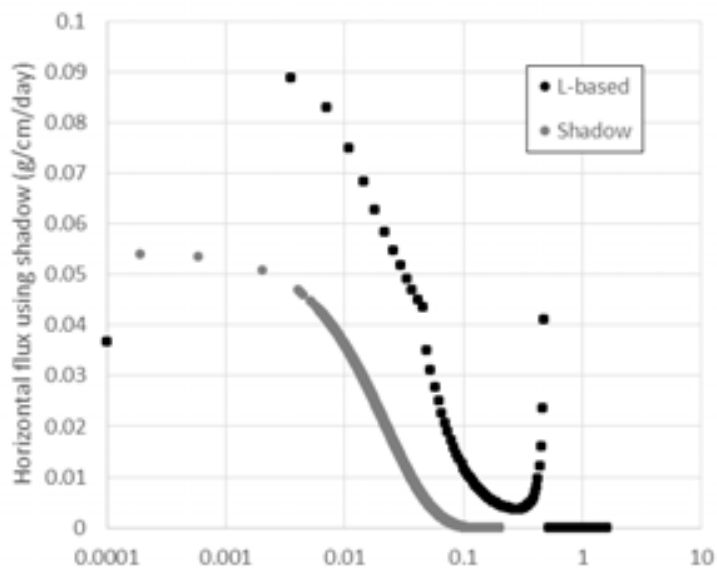

(b)

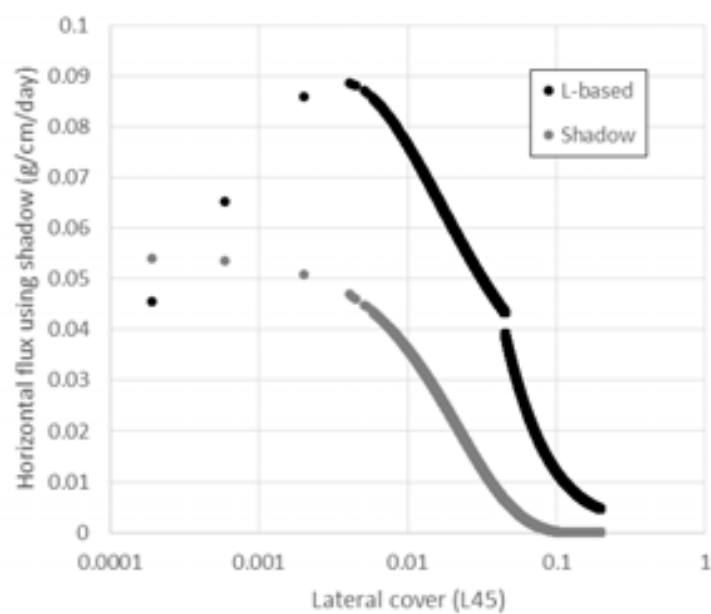

(d)

563 Figure 9. Horizontal flux estimated using the model of Shao et al. (2004) with the traditional lateral cover $\left(L_{45}\right)$ and the new approach using shadow $\left(\omega_{n s}\right)$. The Raupach drag partition model parameters were fixed at $\beta_{v}=$ $170 ; \sigma_{v}=2 ; m_{v}=1$ following Raupach et al. (1993). For simplicity, we assumed that at all pixels (500 $\mathrm{m}$ ) and all times the freestream velocity $U_{f}=20.3 \mathrm{~m} \mathrm{~s}^{-1}$ and the particle size was $63 \mu \mathrm{m}$. We estimated flux using $C L_{45}$ and $\omega_{n s}$, and compared the differences (a). To isolate the major causes of difference in the model we replaced $L_{45}$ with that predicted using $\omega_{n s}$ (b) which removed most of the noise (c) and demonstrated that most of the remaining difference in flux was small (d) and due to small differences in the aerodynamic properties between the two approaches.

\section{1}

\subsection{Estimating sediment transport across scales of variation}

To demonstrate how this albedo-based approach can be used for wind erosion monitoring, we made estimates of $Q_{h}$ (every 8 days) over time (2000-2015) for selected pixels in Australia (Figure 7). These estimates of $Q_{h}$ are made under the same simulated conditions as above and in the previous section and are used here to illustrate the potential $Q_{h}$ averaged monthly (Figure 10a), summed monthly (Figure 10b), averaged annually (Figure 10c) and summed annually (Figure 10d). The largest average monthly flux was produced at the $500 \mathrm{~m}$ pixel or site chosen in Lake Eyre (Figure 7). Similar amounts of average monthly flux was produced consistently over the year at that pixel and also in the Simpson Desert dunes. Flux at the field near Merrinee in the sandy cropping region of New South Wales (NSW) Mallee, and at the sandy agricultural (wheat-sheep) field near Anameka in Western Australia (WA), showed a distinct management practice related decline in flux during the southern hemisphere winterspring. The monthly total flux showed a slightly different pattern. Although the largest flux persists from Lake Eyre, Anameka had similarly large total flux in autumn. This may be associated with grazing of stubble by sheep after the harvest January-February. 
585

(a)

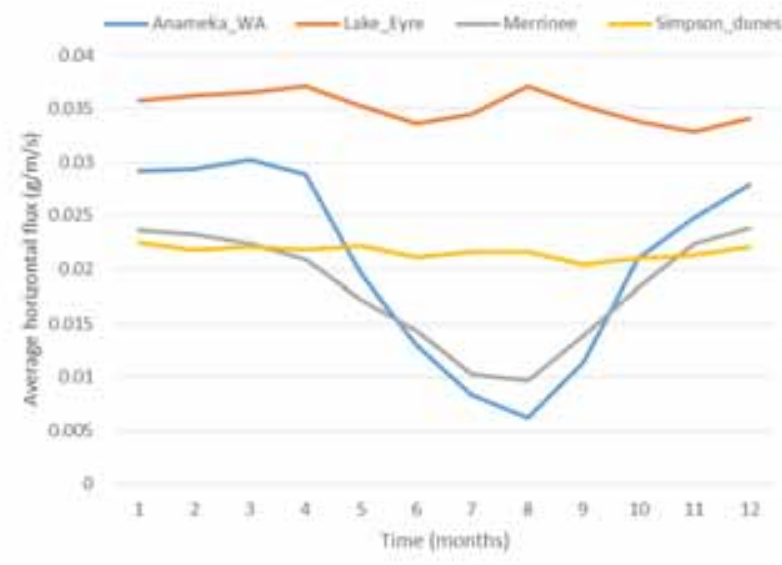

a)

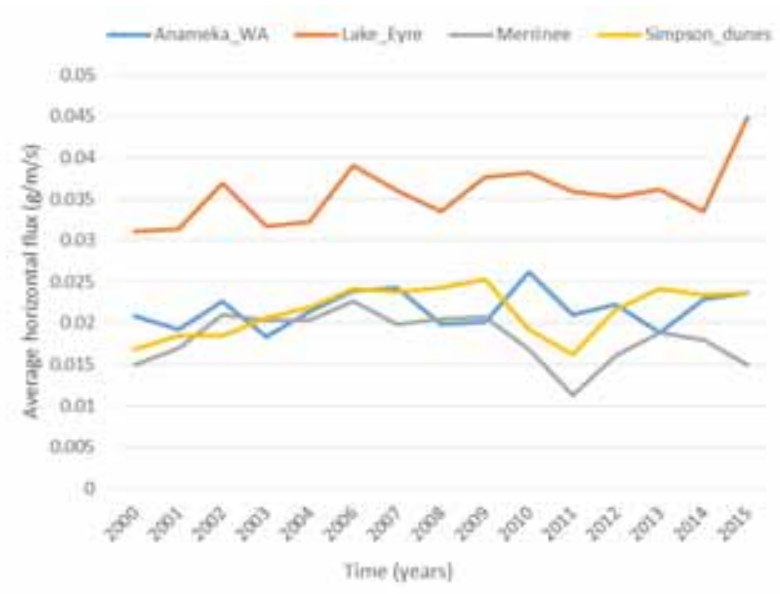

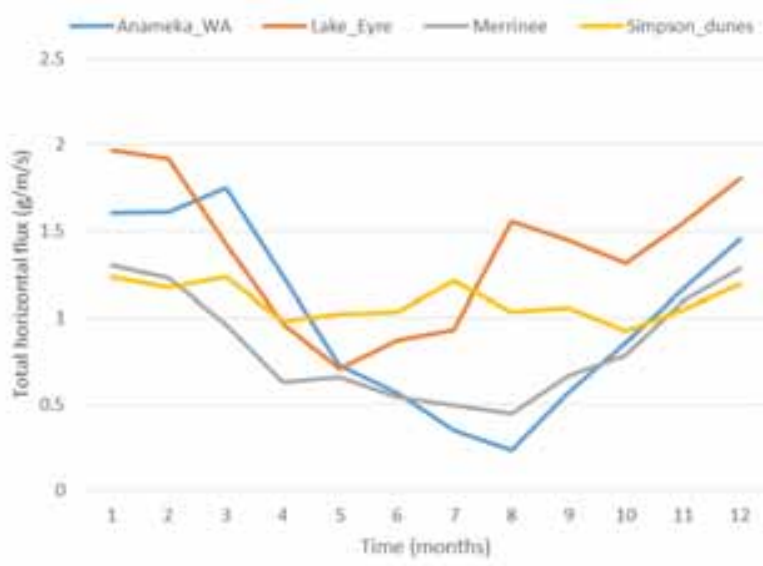

(b)

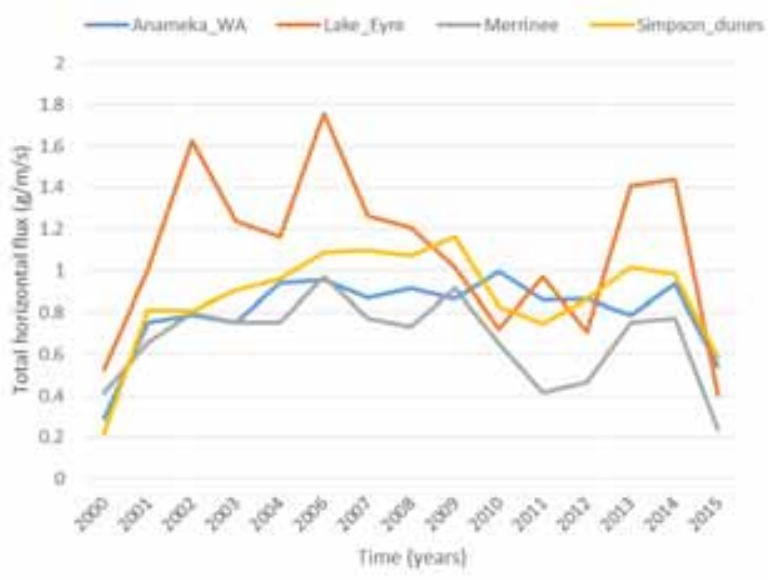

(c) (d)

Figure 10. For locations across Australia showing monthly average (a), and total (b) flux and annual average (c) and total (d) flux estimated with a wind erosion model (Shao et al., 2004) using $\omega_{n s}$.

Recall that $U_{\mathrm{f}}=20.3 \mathrm{~m} \mathrm{~s}^{-1}$ was held constant for the simulations and therefore changes in sediment flux represented the important seasonal and inter-annual variability in surface roughness detected using $\omega_{n s}$. The average annual horizontal flux at the selected locations estimated using $\omega_{n s}$ was shown in Figure 10c. However, the total annual flux provides more information (Figure 10d). The temporal pattern of predicted sediment flux appears to be consistent with measured inter-annual rainfall variability across Australia. Above average rainfall in central and eastern Australia occurred to 2002 and 2010/2011 which contributed to large vegetation cover and small predicted erosion at these times for the Lake Eyre and Merrinee sites. Peaks in predicted sediment transport are consistent with below average rainfall and declines in vegetation cover starting in 2002/2003 through to the large La Niña event in 2010 and subsequent drought in eastern Australia from 2012 through 2015 (http://www.longpaddock.qld.gov.au). Southwestern Australia, around the Anameka site, experienced average or below average rainfall for much of the period 2000-2015, while above average rainfall in 2005/2006 and 2011/2012 appeared not to have a significant effect on the predicted sediment transport rates.

\subsection{The robustness of the empirical albedo-based sediment transport model}

To summarise the performance of the empirical model we compared it with the shadow model and in both cases made predictions of horizontal flux using all of the 25,000 measurements of albedo and hence $\omega_{n s}$ (Figure 11). However, we perturbed both models using randomly generated particle sizes $D(50-500 \mu \mathrm{m})$ and freestream wind velocities $U_{f}\left(0-40 \mathrm{~m} \mathrm{~s}^{-1}\right)$. The results show good general agreement with the shadow model and little response to $D$ in that range. The deviation from the 1:1 line is caused by the difference we noted previously (Figure 5 ). The empirical model (Eq. 8) is not provided as a definitive description of flux, rather it is presented to show that flux 
can be calculated to a reasonable approximation using a straightforward empirical calibration based on $\omega_{n s}$ and $U_{f}$ (notwithstanding the need for $u_{* t s}$ and $H(w)$ ).

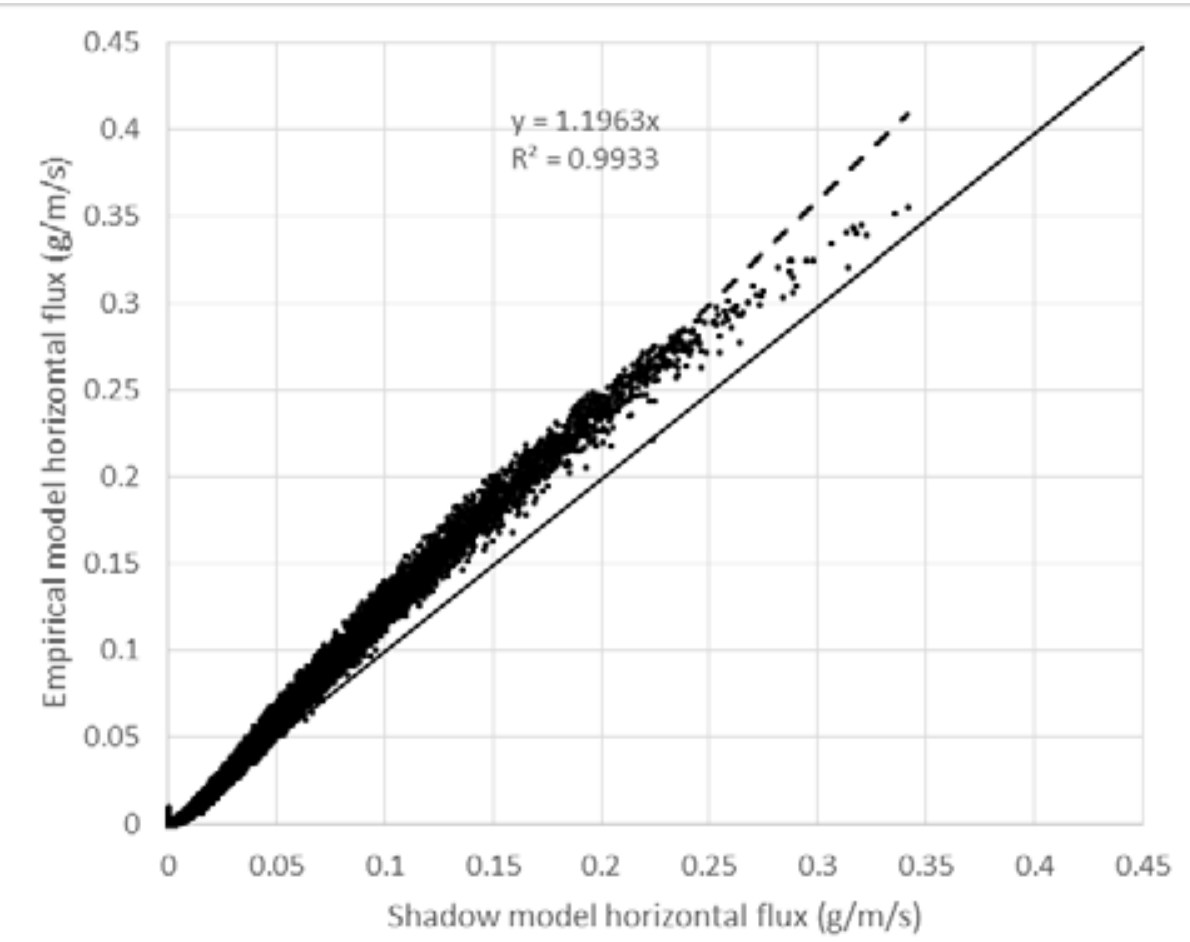

Figure 11. Horizontal sediment flux predicted using the shadow model (Eq. 6) and the empirical model (Eq. 7) using normalised albedo $\left(\omega_{n s}\right)$ at each of the 33 pixels $(500 \mathrm{~m})$ from across the main agro-ecological systems in Australia every 8 days between 2000 to present (around 25000 values). Random numbers for a range of both freestream velocities $\left(U_{f} ; 0-40 \mathrm{~m} \mathrm{~s}^{-1}\right)$ and particle sizes $(D ; 50-500 \mu \mathrm{m})$ were generated for model perturbation (or model testing). A linear regression model was fitted to these data (dashed line) and compared with the 1:1 line (solid).

\section{Implications of using shadow for wind erosion modelling, mapping and monitoring}

\subsection{Benefits of approximating aerodynamic shelter using shadow}

Accurate representation of the turbulent transfer of fluid momentum to the land surface is critical for wind erosion and dust emission modelling. Considerable uncertainty remains, however, in the spatial patterns and magnitude of predicted dust emissions due to the parameterization of surface roughness effects on the drag partition. These uncertainties relate to parameter estimation and scaling, which do not adequately account for the important effects of roughness distribution and wake interactions. The reduced complexity approach of Raupach (1992) was advanced here using albedo to enable an approach for the direct estimation of scalable areaintegrated (areal) estimates of aerodynamic properties from Marshall's (1971) wind tunnel measurements. This approach addresses these uncertainties and provides a common and precise framework across scales (field, region to continent) for investigating aeolian processes in space and time and for improving the accuracy of wind erosion and dust emission models.

Perhaps one of the most influential approximations in dust emission modelling is that surface momentum extraction can be represented by $L_{45}$, the lateral cover of roughness elements (Raupach et al., 1993). We showed here that $L_{45}$ is inadequate to represent the interactions between roughness elements because: (i) its geometric formulation is too simplistic; and (ii) the approximation of sheltering as $L_{45}$ does not allow for shelter areas to interact with downstream roughness elements. The implication is that previous studies which estimated wind erosion using $L_{45}$ have under-estimated $L$ and consequently over-estimated sediment flux. Although this is a bold 
statement, we can be confident that it has occurred because in the traditional Shao scheme $L_{45}$ is pervasive influencing total shear stress $u_{T^{*}}$ (Eq. 12), the boundary layer height del (Eq. 13), $z_{0} / h$ (Eq. 14) and $u_{* t}$ (Eq. 15) because it is based on the Raupach et al. (1993) drag partition correction $R_{t}$ (Eq. 17). The wind erosion scheme of Marticorena and Bergametti (1995) is similarly affected because $L_{45}$ is similarly pervasive there too. The common practice of tuning model predictions against measured sediment flux (parameters $A_{n}$ and cshao; Eqs 16 and 23, respectively) may well have masked this effect. If model parameterisation continues to be of minor consideration by comparison with the emphasis placed on model tuning then wind erosion modelling may simply use an empirical model (like that which we propose here). In contrast, if the purpose of developing and applying physically-based wind erosion models is to improve the understanding of the processes then much less emphasis should evidently be placed on the model tuning. Overall, wind erosion and dust emission models based on $L_{45}$ have hitherto been hindered by its inadequacies, which have been compounded by the difficulties in estimating $L_{45}$ over large areas.

We demonstrated a direct calibration of the normalised surface albedo or its inverse shadow $\left(\omega_{n s}\right)$ to measured aerodynamic properties $\left(z_{0} / h, u_{*} / U_{\mathrm{f}}, R_{t}\right)$. The approach provided a methodology to account for momentum extraction by surface roughness using albedo data. These data are readily measured in an illuminated wind tunnel or the field from standard pyranometers which can 'view' small or large areas depending on their (mast) height and from aircraft or satellite platforms where those data are available globally from MODIS every 8 days at $500 \mathrm{~m}$. These global data will most likely also be available in the near future at $30 \mathrm{~m}$ from bi-directional reflectance parameters (MCD43A) and Landsat Thematic Mapper (TM) and Enhanced Thematic Mapper (ETM+) surface reflectance used to generate Landsat albedo (Shuai et al., 2011). For clarity, the methodology also demonstrated that a single zenith illumination angle at $87^{\circ}$ viewed at nadir could be used instead of albedo to produce an adequate estimate of the aerodynamic properties. In addition to reducing the complexity of wind erosion models, the approach reduces the uncertainties compounded through parameter estimates for the drag partition schemes. Critically, the approach provides areal information for each pixel that is sensitive to roughness distribution.

\subsection{Reduced complexity leading to new opportunities in aeolian research}

Of greatest significance is the evident redundancy of information used in the current wind erosion schemes. We showed how the four aerodynamic parameters in the original, widely used Shao wind erosion scheme $\left(L_{45}, R_{t}\right.$, $u_{*} / U_{f}$ and $z_{0} / h$; Eq. 5) can be reduced (Eqs. 23-25) so that only $u_{s^{*}} / U_{f}$ is needed to estimate sediment mass flux. This approach also ensures consistency in the predictions of surface shear stress (previously via $z_{0} / h$ and often externally sourced) with measurements of $\omega_{n s}$. We found that small changes to the parameters of the Raupach drag partition scheme had a considerable influence on the flux estimates. Furthermore, our results (Figure 4) show that total shear stress $\left(u_{T^{*}}\right)$ should not be used to estimate mass flux with the Raupach drag partition because flux inappropriately increases with increasing lateral cover (cf Webb et al., 2014). With the correct drag partition, the use of measured $u_{T^{*}}$ from within rough canopies (e.g., wind velocity profile in a vegetated area) or even modelled $u_{T^{*}}$ for a pixel of rough canopies will over-estimate flux. In these situations, $u_{T^{*}}$ should be converted to $u_{S^{*}}$ using $R_{t}$, with $R_{t}$ obtained from the calibration with $\omega_{n s}$. Combining the precision of the wind tunnel calibration with the precision of $\omega_{n s}$ measurements should reduce considerably the uncertainty in modelled sediment mass flux for a range of platforms and across scales. The implication is that measurements of (or modelled) $\omega_{n s}$ can be used to predict areal flux with information on only $U_{f}$. Notably, there is scope to retrieve $D$ from remote sensing and more specifically using bi-directional soil reflectance modelling (Pinty et al., 1989; Okin and Painter, 2004; Chappell et al., 2007; Wu et al., 2009). Similarly, soil moisture is also readily retrieved from reflectance measurements (e.g., Soil Moisture Active Passive satellite; global every $9 \mathrm{~km}$ and every 7 days). The combination of these additional measurements with the approach described here would finally enable remote sensing of wind erosion (Chappell et al., 2006).

The simplicity of our remote sensing approach presents new opportunities for modelling, mapping and monitoring of wind erosion. For example, our new approach is readily applicable to large area global or regional land surface models (LSMs) which currently do not include any wind erosion and therefore no feedbacks between 
the loss (or gain of soil) and changes to soil biogeochemical (e.g., C cycling) or biophysical processes (e.g., infiltration or moisture holding capacity) and which may have profound impacts on models and their outcomes (Chappell et al., 2015; Katra et al., 2016). The many and varied applications of e.g., Revised Wind Erosion Equation (RWEQ) could be similar targets for our empirical wind erosion model based on MODIS albedo and would require far fewer parameters and input data layers. Facilitating the adoption of wind erosion models by other research communities will raise awareness of the significance of wind erosion and provide new and collaborative opportunities for integrating aeolian research in to Earth System Models (Shao et al., 2011) and agriculturalsystem sciences.

\subsection{Current limitations in sediment flux modelling}

Perhaps the greatest weakness of our work is that the new models are not demonstrated against measured sediment flux. Instead they are compared with sediment flux calculated from the aerodynamic measurements of Marshall's (1971) wind tunnel. Nonetheless, this approach enables perhaps the greatest precision possible in the calculation of sediment flux (particularly areal fluxes) because of the carefully controlled laboratory conditions of Marshall's (1971) data evident from its enduring use in the literature. Our new approach improved upon the existing modelling approach in terms of the identified weaknesses and redundancy in information content. However, it did not enable an examination of the nature or form of the model which could arise when compared with compatible areal sediment flux measurements. These types of areal flux measurements are, to our knowledge, not available. We also recognise that the sediment transport equation we modified for use with areal $\omega_{n s}$ measurements has evolved from point measurements. It could be argued that we should have used existing point flux measurements regardless. However, we believe that this would introduce considerable uncertainty to the comparison because of the large spatial variability in point flux measurements within a given area (Webb et al., 2016). Our implication is therefore that existing flux measurements do not adequately represent areal sediment flux estimates because of the following, all too common, sampling problems associated with their measurement:

(1) too few sediment flux samples are used to adequately estimate the average for a given area, and typically as the area increases so the variability increases (to some point = spatial dependence);

(2) sampling variance is not quantified and consequently there is no information to inform the number of samples to use and to contribute to a rigorous framework for detecting change or difference (over time and / or in space);

(3) inherent bias in existing sampling towards locations where flux occurs - for a given area, flux is measured away from large (vegetation) roughness elements biasing the average flux towards an environment without those influences.

Solutions to these sampling problems have been developed over the last 10 years in soil science and have already been applied in aeolian research and other fields (Chappell et al., 2003a \& b; Li et al., 2015; Chappell et al., 2015). We suggest that these solutions should become a routine and essential component of field work in aeolian research. For examples, a new national programme of wind erosion monitoring in the USA (Webb et al. 2015, 2016) has used rigorous sampling designs. When these and other unbiased estimates of areal sediment flux are available in the near future, it would be timely to revisit the point-based sediment transport equation and evaluate a new form for areal sediment flux and validate our shadow-based approach.

\subsection{Challenges for future aeolian research}

It is important to note that our work and that of others before us (e.g., Raupach's drag partition) is built on the foundation that the results of wind tunnel experiments are general or universal across scales. To our knowledge this is assumed in most aeolian research and particularly in sediment transport and dust emission modelling. On this basis, the main strength of our reduced-complexity approach to estimating aerodynamic properties and sediment mass flux is the link between the precision of wind tunnel studies and the precise and scalable measurement (or bi-directional reflectance models) of albedo that enable area-integrated (areal) estimates of aerodynamic properties. We showed (in several ways e.g., Figure 9a) that using $\omega_{n s}$ to establish the key 
aerodynamic properties improved the precision with which flux can be estimated using an existing wind erosion scheme. The main benefit shown here was in replacing the use of $L_{45}$. However, under different circumstances it is very likely that the disconnection of the aerodynamic roughness and wind friction velocity $(u *)$ by the use of separate external modelling resources would most likely be a source of considerable uncertainty. With the shadow model, that disconnection is unnecessary and therefore the uncertainty is eliminated. Here we showed that the largest uncertainty in sediment flux was caused by the precision of Marshall's (1971) aerodynamic measurements. The influence of roughness configuration on the sediment flux estimates was removed by avoiding $L_{45}$ and the Raupach drag partition scheme. Under the simulated conditions, we reported an uncertainty of area-integrated (areal) sediment flux to be approximately $0.01 \mathrm{~g} \mathrm{~m}^{-1} \mathrm{~s}^{-1}$. That precision is repeatable over large areas and in different locations using measurements of albedo and our shadow model, because of its direct calibration and thereby the inherited precision of Marshall's (1971) wind tunnel experiments.

Consequently, this work suggests a future testable hypothesis that there is more precision (less uncertainty) in this albedo-based approach to the estimation of areal aerodynamic properties and sediment flux than there is using current approaches to field measurements particularly if they use a single wind velocity profile in heterogeneous roughness to estimate $u_{T^{*}}$ and represent its variation for an unknown contributing area of roughness. This hypothesis represents a challenge to the aeolian research community to quantify the complete uncertainty of the wind erosion measurement 'system' which will identify areas of field-based research which need to be strengthened to avoid misleading conclusions about detecting change in space and time.

\section{Acknowledgements}

Funding from the Australian Wool Innovation Ltd for a project on 'Increasing wool sheep in cropping zones' and from the CSIRO Land and Water provided the time for AC to develop some of the bases for this research. We also acknowledge support for NPW from the USDA Natural Resources Conservation Service, Conservation Effects Assessment Project, for the development of new wind erosion decision-support tools. We are grateful to Prof. Yaping Shao, for providing funding for valuable discussions which enabled the development of some bases of the research. We are grateful for access to the Google Earth Engine which enabled the global processing and visualisation and the support provided by the Google Developers. We thank Juan Pablo Guerschman for the MODIS data manipulation and Drs. Harry Butler, lan Harmon, Martina Klose and Kerstin Schepanski for their valuable comments on an earlier manuscript. The comments by two anonymous reviewers during the journal review process are much appreciated. Any errors remaining in the manuscript are the responsibility of the authors.

\section{References}

Alfaro, S. C., and Gomez, L. (1995). Improving the large-scale modelling of the saltation flux of soil particles in the presence of non-erodible elements. Journal of Geophysical Research, 100, 16357-16366.

Bagnold, R.A., (1941). The Physics of Blown Sand and Desert Dunes. Methuen, London.

Brown, S., W. G. Nickling, and J. A. Gillies (2008) A wind tunnel examination of shear stress partitioning for an assortment of surface roughness distributions, J. Geophys. Res., 113, F02S06, doi:10.1029/2007JF000790.

Chappell, A. and Heritage, G.L. (2007) Using illumination and shadow to model aerodynamic resistance and flow separation: An isotropic study. Atmospheric Environment, 41(28), 5817-5830. http://dx.doi.org/10.1016/j.atmosenv.2007.03.037.

Chappell, A., Baldock, J., Sanderman, J. (2015) The global significance of omitting soil erosion from soil organic carbon cycling models. Nature Climate Change Dec 2015; (Published online 26 Oct 2015; http://dx.doi.org/10.1038/nclimate2829

Chappell, A., Dong, Z., Van Pelt, S., and Zobeck, T. (2010). Estimating aerodynamic resistance of rough surfaces using angular reflectance. Remote Sensing of Environment, 114 (no. 7): 1462-1470. http://dx.doi.org/10.1016/j.rse.2010.01.025 
Chappell, A., Li, Y., Yu, H., Zhang, Y.Z., Li., X.Y. (2015) Cost-effective sampling of ${ }^{137}$ Cs-derived net soil redistribution: Part 2 - estimating the spatial mean change over time. Journal of Environmental Radioactivity 141: 168-174. http://dx.doi.org/10.1016/j.jenvrad.2015.02.015

Chappell, A., McTainsh, G., Leys, J. and Strong, C. (2003). Simulations to optimise sampling of aeolian sediment transport for mapping in space and time. Earth Surface Processes and Landforms, 28: 1223-1241. http://dx.doi.org/10.1002/esp.1036

Chappell, A., McTainsh, G., Leys, J. and Strong, C. (2003). Using geostatistics to elucidate temporal change in the spatial variation of aeolian sediment transport. Earth Surface Processes and Landforms, 28: 567-585. http://dx.doi.org/10.1002/esp.463

Chappell, A., Zobeck, T.M., Brunner, G. (2006). Using bi-directional soil spectral reflectance to model soil surface changes induced by rainfall and wind-tunnel abrasion. Rem. Sens. Environment. 102(3-4): 328-343. http://dx.doi.org/10.1016/j.rse.2006.02.020

Chappell, A., Strong, C., McTainsh, G. and Leys, J. (2007). Detecting induced in situ erodibility of a dust-producing playa in Australia using a bi-directional soil spectral reflectance model. Remote Sensing of Environment, 106: 508-524. http://dx.doi.org/10.1016/j.rse.2006.09.009

Charru, F., Andreotti, B., Claudin, P., (2013). Sand ripples and dunes. Annu. Rev. Fluid Mech. 45, 469-493.

Crawley, D. M., and W. G. Nickling (2003), Drag partitioning for regularly-arrayed rough surfaces, Boundary Layer Meteorol., 107, 445-468.

Duran, O., Claudin, P., Andreotti, B., (2011). On aeolian transport: grain-scale interactions, dynamical mechanisms and scaling laws. Aeol. Res. 3, 243-270

Gillette, D. A., and P. H. Stockton (1989), The effect of nonerodible particles on wind erosion of erodible surfaces, J. Geophys. Res., 94,12,885-812,893.

Gillette, D. A., J. E. Herrick, and G. Herbert (2006), Wind characteristics of mesquite streets in the northern Chihuahuan Desert, New Mexico, U.S.A., Environ. Fluid Mech., 6, 241-275

Gillies, J. A., N. Lancaster,W. G. Nickling, and D. M. Crawley (2000), Field determination of drag forces and shear stress partitioning effects for adesert shrub (sarcobatus vermiculatus, greasewood), J. Geophys. Res., 105(D20), 24,871-24,880.

Gillies, J. A., W. G. Nickling, and J. King (2007), Shear stress partitioning in large patches of roughness in the atmospheric inertial sublayer. Boundary Layer Meteorol., 122, 367-396.

Goossens, D., Gross, J. and Spaan, W. (2001), Aeolian dust dynamics in agricultural land areas in Lower Saxony, Germany. Earth Surf. Process. Landforms, 26: 701-720. doi: 10.1002/esp.216

Jenkins, J.T., Valance, A., (2014). Periodic trajectories in Aeolian sand transport. Phys. Fluids Am. Inst. Phys. (AIP) 2014, 073301.

Katra, I., Gross, A., Swet, N., Tanner, S., Krasnov, H., Angert, A. (2016) Substantial dust loss of bioavailable phosphorus from agricultural soils. Scientific Reports, 6:24736 | DOI: 10.1038/srep24736

King, J., W. G. Nickling, and J. A. Gillies (2006), Aeolian shear stress ratio measurements within mesquitedominated landscapes of the Chihuahuan Desert, New Mexico, U.S.A., Geomorphology, 82, 229-244.

Lancaster, N. (2013). Geomorphology of Desert Dunes. Routledge, New York

Lancaster, N., and A. Baas (1998), Influence of vegetation cover on sand transport by wind: Field studies at Owens Lake, California, Earth Surface Processes and Landforms, 23, 69-82

Li, Y., Chappell, A., Nyamdavaa, B., Yu, H., Davaasuren, D., Zoljargal, K. (2015) Cost-effective sampling of ${ }^{137} \mathrm{Cs}-$ derived net soil redistribution: Part 1 -estimating the spatial mean across scales of variation. Journal of Environmental Radioactivity 141:97-105. doi:10.1016/i.jenvrad.2014.12.007

Marshall, J. K. (1971). Drag measurements in roughness arrays of varying density and distribution. Agricultural Meteorology, 8, 269-292.

Marticorena, B., \& Bergametti, G. (1995). Modeling the atmospheric dust cycle: 1. Design of a soil-derived dust emission scheme. Journal of Geophysical Research, 100(D8), 16415-16430.

MacKinnon, D.J., Clow, G.D., Tigges, R.K., Reynolds, R.L. and Chavez, P.S.Jr. (2004). Comparison of aerodynamically and model-derived roughness lengths (z0) over diverse surfaces, central Mojave Desert, California, USA. Geomorphology 63(1-2):103-113, doi:10.1016/j.geomorph.2004.03.009

Okin, G.S. and Painter, (2004) Effect of grain size on remotely sensed spectral reflectance of sandy desert surfaces. Remote Sensing of Environment, 89: 272 - 280 
Okin, G.S., Heras Mariano Moreno-de, Saco Patricia M., Throop H.L., Vivoni Enrique R., Parsons Anthony J., Wainwright John, and Peters Deb (2015). Connectivity in dryland landscapes: shifting concepts of spatial interactions, Frontiers in Ecology and the Environment, 02/2015, Volume 13, Issue 1, p.20-27.

Shao Y, Bergametti G, Chappell A, Findlater P, Gillies J, Ishizuka M, Klose M, Kok J, Leys J, Lu H, Marticorena B, McTainsh G, McKenna-Neuman C, Nickling W, Okin G, Strong C, Webb NP. (2015) A Tribute to Michael R Raupach for Contributions to Aeolian Fluid Dynamics. Aeolian Research, Vol. 19, 37-54. doi:10.1016/j.aeolia.2015.09.004

Shao, Y. (2004), Simplification of a dust emission scheme and comparison with data, J. Geophys. Res., 109, D10202, doi:10.1029/2003JD004372.

Shao, Y., Wyrwoll, K.-H., Chappell, A., Huang, J., Lin, Z., McTainsh, G., Mikami, M., Tanaka, T., Wang, X., and Yoon, S. (2011). Dust cycle: An emerging core theme in Earth system science. Aeolian Research, 2 (no. 4): 181204. http://dx.doi.org/10.1016/j.aeolia.2011.02.001

Shuai, Y, Masek, J.,G., Gao, F., Schaaf, C.B. 2011. An algorithm for the retrieval of 30-m snow-free albedo from Landsat surface reflectance and MODIS BRDF. Remote Sensing of Environment 115: 2204-2216.

Smith, M.W., Quincey, D.J., Dixon., T., Bingham, R.G., Carrivick, J.L., Irvine-Fynn, T.D.L. and Rippin, D.M. (2016). Aerodynamic roughness of glacial ice surfaces derived from high resolution topographic data (accepted).

Webb NP, Okin GS, Brown S, (2014). The effect of roughness elements on wind erosion: the importance of surface shear stress distribution. Journal of Geophysical Research Atmospheres. Vol. 119, 6066-6084. doi:10.1002/2014JD021491

Webb NP, Strong CL, (2011). Soil erodibility dynamics and its representation for wind erosion and dust emission models. Aeolian Research, Vol. 3, 165-179. doi:10.1016/j.aeolia.2011.03.002

Webb, N.P., Herrick, J.E., Hugenholtz, C.H., Zobeck, T.M., Okin, G.S., (2015). Standard Methods for Wind Erosion Research and Model Development: Protocol for the National Wind Erosion Research Network. USDA-ARS Jornada Experimental Range, Las Cruces, New Mexico.

Webb, N.P. Herrick, J., Van Zee, J., Courtright, E., Hugenholtz, C., Zobeck, T. M., Okin, G. S., Barchyn, T. E., Billings, B. J., Boyd, R., Clingan, S., Cooper, B., Duniway, M. C., Derner, J. D., Fox, F. A., Havstad, K. M., Heilman, P., LaPlante, V., Ludwig, N. A., Metz, L. J., Nearing, M. A., M. Norfleet, L., Pierson, F. B., Sanderson, M. A., Sharratt, B. S., Steiner, J. L., Tatarko, J., Tedela, N. H., Toledo, D., Unnasch, R. S., R. Van Pelt, S., and Wagner, L., (2016) The National Wind Erosion Research Network: Building a standardized long-term data resource for aeolian research, modeling and land management, Aeolian Research, vol. 22, pp. 23-36.

Wolfe, S. A., and W. G. Nickling (1996), Shear stress partitioning in sparsely vegetated desert canopies, Earth Surf. Processes Landforms, 21,607-619.

Wooding, R. A. Bradley, E. F. Marshall J. K. (1973) Drag due to regular arrays of roughness elements of varying geometry Boundary-Layer Meteorology, 5 (3): 285-308

Wu, Y., Gong, P., Liu, Q., and Chappell, A., (2009). Retrieving photometric properties of desert surfaces in China using the Hapke model and MISR data. Remote Sensing of Environment 113 (1): 213-223. http://dx.doi.org/10.1016/j.rse.2008.09.006 